\title{
High-Resolution Geoacoustic Characterization of the Seafloor Using a Subbottom Profiler in the Gulf of Lion
}

\author{
Gwladys Theuillon, Yann Stéphan, and Anne Pacault
}

\begin{abstract}
Subbottom profilers are commonly used to explore the first sediment layers below the seafloor. Recent narrowbeam profilers achieve improved performances in terms of signal-to-noise ratio (SNR) and resolution. Thus, the potential of these systems for near real-time geoacoustic characterization of sediments is high and is worth being specifically explored. This paper presents several methods to estimate geoacoustic parameters such as the absorption, the reffectivity, and the impedance contrast. These procedures are tested against real data collected with the SBP 120 subbottom profiler during the CALIbration MEthodology for Recognition of the Ocean bottom (CALIMERO) experiment. It is shown that the absorption and impedance contrast estimates are fully consistent with in situ measurements, which tends to confirm the possibility of near real-time characterization of sediment layers.
\end{abstract}

Index Terms-Absorption, Eckart's model, geoacoustic inversion, impedance contrast, spectral ratio, subbottom profiler.

\section{INTRODUCTION}

$\mathbf{T}$ HE geoacoustic characterization of the seafloor and the sedimentary layers can be obtained from a large panel of observation systems such as sidescan sonars, multibeam echosounders, 'seismic profilers, or geoacoustic inversion systems. However, none of these systems on its own is able to fully infer the geoacoustic parameters. Combining all systems is then an attractive idea provided that methods of systems intercalibration and data fusion can be developed. This is the aim of the CALIbration MEthodology for Recognition of the Ocean bottom (CALIMERO) project [1] jointly conducted by Service Hydrographique et Océanographique de la Marine (SHOM, Brest, France) and the French Institute for Research and Sea Exploration (IFREMER, Plouzané, France). The first step of the CALIMERO project is to collect a reference data set with the largest panel of available instruments and develop

Manuscript received October 8, 2007; revised March 4, 2008; accepted May 26, 2008. First published December 11, 2008; current version published January 16, 2009. This work was supported in part by "Région Bretagne" under the framework of the Contrat-Plan-Etat-Région in seismo-acoustics and by the French Defence Procurement Agency (DGA) under the framework of the PEA032402 research program on acoustic Rapid Environmental Assessment (REA).

Associate Editor: R. Chapman.

G. Theuillon and Y. Stéphan are with Service Hydrographique et Océanographique de la Marine (SHOM), 29228 Brest cedex 2, France (e-mail: gwladys.theuillon@shom.fr; yann.stephan@shom.fr).

A. Pacault is with French Institute for Research and Sea Exploration (IFREMER), 29280 Plouzané, France (e-mail: anne.pacault@ifremer.fr).

Digital Object Identifier 10.1109/JOE.2008.926958 geoacoustic characterization procedures, specific to each instrument. The second step, which is still way ahead, consists in merging data and developing ad hoc data fusion methods to take advantage of the complementarity and redundancy of the systems to reconstruct a unique 3-D image of the bottom surface and interior sublayers.

In this paper, we focus on the use of a subbottom profiler to estimate geoacoustic parameters such as the absorption and reflection coefficients, the impedance contrast, and microroughness. The motivation of this work lies in the fact that geoacoustic parameters are generally difficult to obtain. On one hand, the measurement on the in situ samples is local, heavy, and destructive. On the other hand, the geoacoustic inversion systems in a "through-the-sensor" fashion [2]--[6] are attractive, but they suffer from poor sensitivity and nonumiqueness. Moreover, the instrumentation is still relatively heavy to handle. In this work, we aim to evaluate the potential of subbottom profilers, generally handy and mountable on small ships or even autonomous underwater vehicles (AUVs), to provide bottom parameters estimates hopefully in near real-time for each sediment layer along a track. This work is a contribution to Rapid Environmental Assessment (REA), which is basically a military concept to rapidly and accurately support naval operations in poorly known environments.

This paper is organized as follows. In Section II, the experimental setup is described. An overview of the CALIMERO experiment is presented and the data recorded by the subbottom profiler are described. Section III deals with the methods that have been developed to process subbottom profiler data. First, we present an algorithm for automatic reflector detection and tracking; this algorithm is driven by a Markov random field approach. Then, we present the inversion methods for absorption, the impedance contrast, and microroughness. The inversion of the absorption coefficient relies on spectral ratio analysis. The impedance contrast and microroughness are derived from the reflection coefficient given by Eckart's classical model. Section IV presents the results on the CALIMERO data set. The results are compared to ground truth measurement and other sensors to prove the validity of the proposed methods. Conclusions and perspectives are drawn in Section V.

\section{CALIMERo EXPERTMENT AND SBP 120 MAN FEATURES}

\section{A. The CALIMERO Experiment Area}

The CALIMERO experiment took place in the Gulf of Lion, on the southern coast of France (see location in Fig. 1). Three 


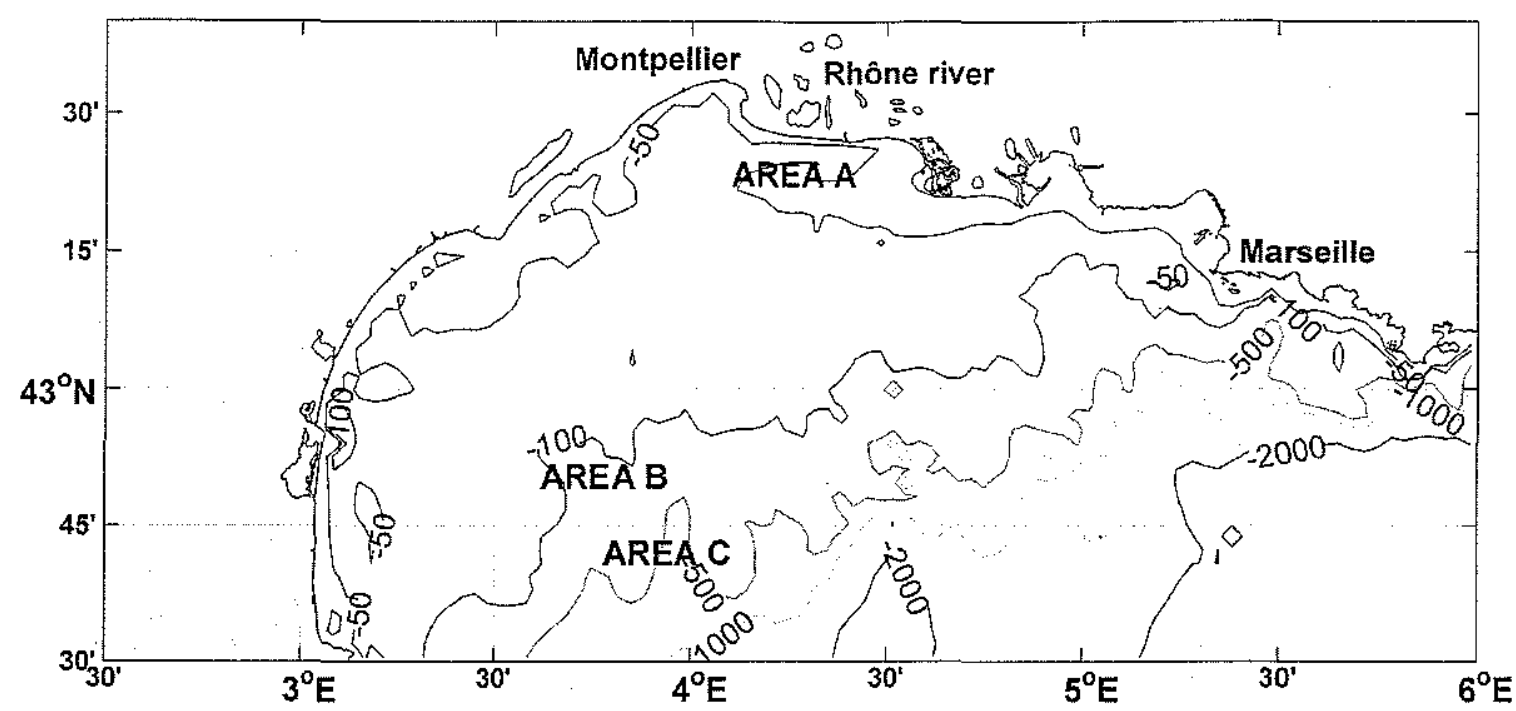

Fig. 1. Map of the CALIMERO area. Three areas (A, B, and C) were surveyed.

areas, with different bathymetric and sedimentary features, were surveyed; each area was about $10 \times 10 \mathrm{~km}^{2}$.

- Area $\mathrm{A}$ is a shallow water area (30-80-m depth) close to the French coast; south of the Rhône river delta. It features a very flat topography, the depth difference corresponding to the overall slope of the continental shelf towards the southwestern direction. The only noticeable bathymetric event is a strip of sandy waves in the middle part of the area.

- Area B is located in deeper water $(100-200 \mathrm{~m})$. It is a gradual transition from sandy to muddy seafloors from north to south. It features a local rising, the so-called Roche de Sète, which corresponds to a very porous coarse sand conglomerate. Gently sloping globally, the area in the southwestern corner intersects the head of Aude Canyon, with a much more uneven topography. The area is centered on the PRomess Gulf of Lion 2 (PRGL-2) drilling point of the PROfiles across MEditerranean Sedimentary Systems (PROMESS) project [7].

- Area $\mathrm{C}$ is located over the river Aude canyon. It features very strong slopes with depth varying between 150 and $550 \mathrm{~m}$. The area is centered on the PRGL-1 drilling point of the PROMESS project.

\section{B. Data Acquisition Methodology}

Three complementary cruises have been conducted over the three areas:

- CALIMERO-1, onboard the French Navy Hydrographic and Oceanographic Vessel Beautemps-Beaupré in September 2004;

- CALIMERO-2, onboard IFREMER Oceanographic Vessel Le Surôt in May 2005;

- CALIMERO-3, onboard IFREMER Oceanographic Vessel L'Atalante in September 2006.

The interest of using several ships was to operate as many systems as possible. The list of available measurements is given in Fig. 2; three multibeam echosounders operating at different frequencies, a sidescan sonar, several high-resolution seismic equipments, and a very low-frequency (VLF) transmission system (a towed source and a bottom moored vertical line array) were used. Hydrological measurements (currents, sound-speed profiles, tides, etc.) and sedimentary measurements (grabs and cores) were also collected.

The surveyed tracks on the three areas are represented in Fig. 3.

\section{The SBP 120 Subbottom Profiler}

1) Description: The SBP 120 multibeam subbottom profiler, developed by Kongsberg Maritime (Kongsberg, Norway) and installed onboard the French Navy hydro-oceanographic vessel Beautemps-Beaupré, operates with two large arrays used for emission and reception mounted in a Mills cross configuration. At $4 \mathrm{kHz}$, the resulting two-way beam pattern is $3^{\circ} \times 3^{\circ}$. The frequency band of the system is $2.5-7 \mathrm{kHz}$. Although various signal types can be emitted, linear chirps are most commonly used because of their good performance in terms of signal-tonoise ratio (SNR) improvement. A detailed description of the SBP 120 subbottom profiler is given in [8] and [9].

2) Performance: For chirp signals, the nominal vertical time resolution is given by $1 / B$, where $B$ is the frequency bandwidth. Theoretically, for linear frequency modulations between 2.5 and $7 \mathrm{kHz}$, the resolution is about 0.22 -ms two-way time (TWT), which corresponds to $17, \mathrm{~cm}$ for a sound speed of $1500 \mathrm{~m} / \mathrm{s}$. Experimentally, vertical resolutions lower than $0.35 \mathrm{~ms}$ have been actually observed on recordings.

The use of a large array for transmission with up to 96 transducers provides a high source level (above $220 \mathrm{~dB}$ re $1 \mu \mathrm{Pa}$ @ $1 \mathrm{~m}$ in the frequency band), a high directivity, and a good SNR. The theoretical penetration depth was estimated using sonar equation for a homogeneous horizontal layer of sediments lying on a hard basement. Detailed results showing the penetration depth as a function of sediment absorption are presented in [9]; these results are consistent with the penetration up to $100 \mathrm{~m}$ actually achieved at sea in soft sediments. 


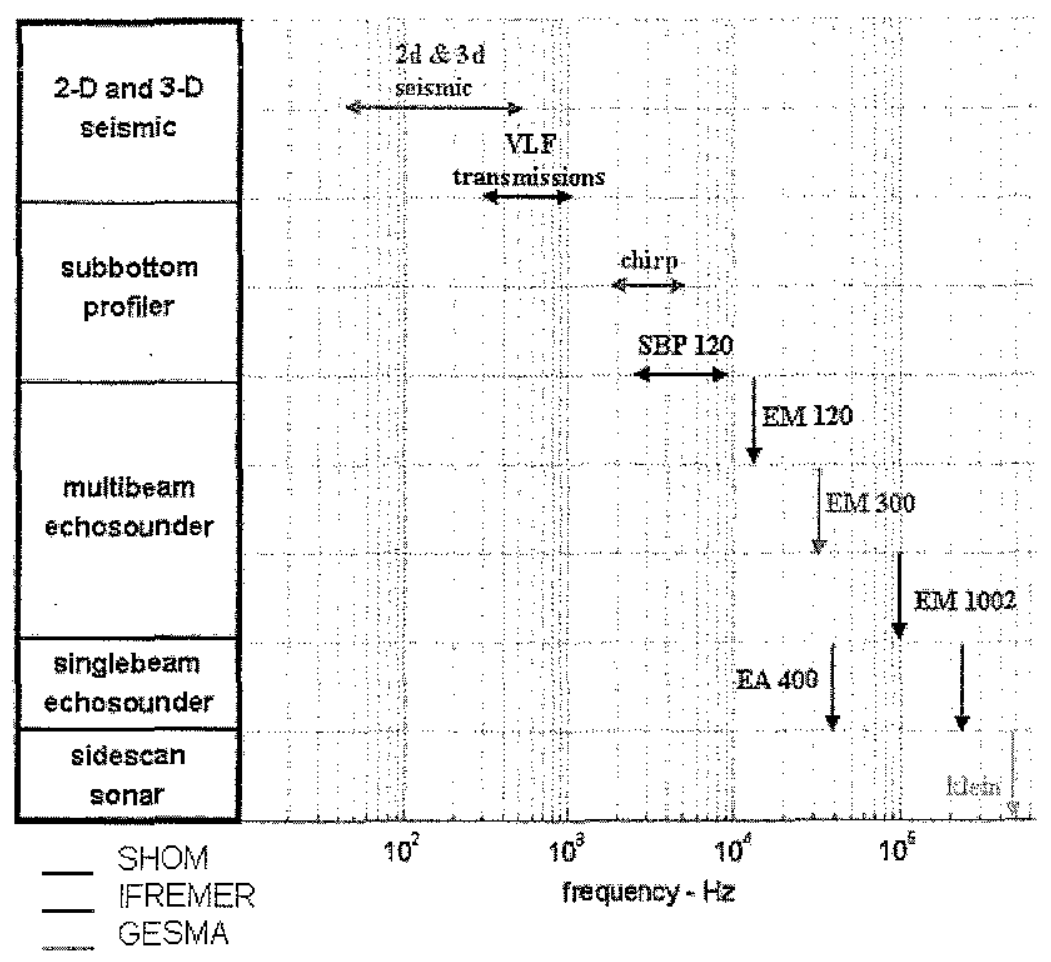

Fig. 2. Sensors operated during the CALIMERO experiment with corresponding frequencies.

3) Acquisition Configuration: Subbottom profilers exploit the specular echo returned by the acoustic impedance discontinuities. It is then necessary to make sure that the echo comes from the coherent reflection. In the SBP 120 frequency bandwidth and for narrowbeams, the coherent component is preponderant compared to the bottom scattering [10]. For the environments relevant to this study, it is shown on real data in [9] that nonspecular backscattering from the seafloor and underlying interfaces is indeed a negligible part of the total energy received. Thus, the characterization of the geoacoustic parameters is possible provided the specular echo is correctly recorded. For this purpose, when imaging the complex structures or the sloping seafloor, the size of the arrays (i.e., the number of active transducers) must be reduced to increase the beamwidth, because the angle between the axis of the receiving beam and the specular direction must remain within half the beamwidth for successfully recording the coherent reflection [8].

During the CALIMERO experiment, the acquisition configuration was set as follows:

- in area A, half of the transmitting $(\mathrm{Tx})$ and receiving $(\mathrm{Rx})$ active transducers have been used (providing a $6^{\circ} \times 6^{\circ}$ two-way beam pattern) to work in the far field and the emitted signals were 20-ms-long linear chirps;

- in area $\mathrm{B}$, all active transducers have been used providing a $3^{\circ} \times 3^{\circ}$ two-way beam pattern and the emitted signals were 40 -ms-long linear chirps;

- in area $\mathrm{C}$, a quarter of $\mathrm{Tx}$ and $\mathrm{Rx}$ active transducers have been used (providing a $12^{\circ} \times 12^{\circ}$ two-way beam pattern) to record correctly the reflected signal on sloping seafloors and the emitted signals were 40-ms-long linear chirps.

4) Preprocessing: During the acquisition, raw data have been recorded after beamforming. Before estimating the geoa- coustic parameters, several preprocessing steps are applied. First, raw data are corrected from the source level, the receiving sensitivity, and the receiver gains. Then, the time series are obtained by cross correlating the received signal with the theoretical emitted chirp. Finally, a correction of the geometrical spreading is applied. An example of acquisition along a track is given in Fig. 4.

5) Calibration: The source level, the receiving sensitivity, and the receiver gains were measured by the manufacturer in a $\operatorname{tank}$ (the measurement of the source level with a $12^{\circ} \times 12^{\circ}$ beam and separate measurements of the sensitivity and preamplifier gain of a few receiving transducers). The source level used for processing was extrapolated from the $12^{\circ} \times 12^{\circ}$ beam measurements to a $3^{\circ} \times 3^{\circ}$ and a $6^{\circ} \times 6^{\circ}$ beam. The error for the source level might be quite important: with large arrays, the far-field conditions are difficult to reach, especially for high frequencies. Moreover, reverberation in the measurement tank might also have distorted the results, particularly at low frequencies, so the source level of the array after integration on the hull could be different from the level measured.

The receiver sensitivity used for processing was estimated with the mean value of the available measurements. Some recordings of raw data before beamforming show that the sensitivity of the 64 receiving transducers is quite similar and this approximation seems to be acceptable. However, this sensitivity could have changed after integration of the array on the hull, and once again, the values for the low frequencies are not reliable because of the limitation in the measurement facilities.

As will be shown below, no level calibration is needed to estimate the absorption coefficient because the latter can be deduced from spectral ratios icf., Section III-C for detailed 


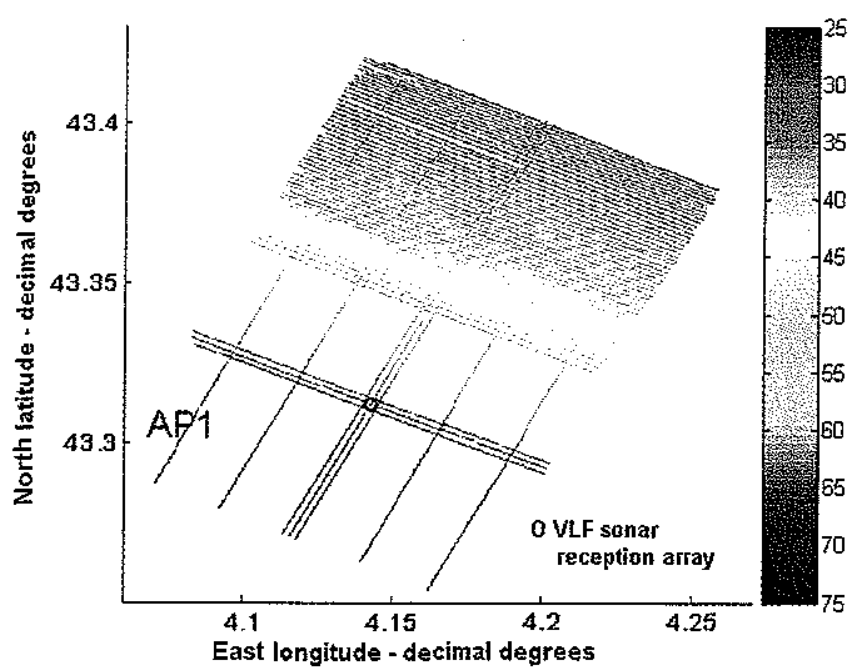

(a)

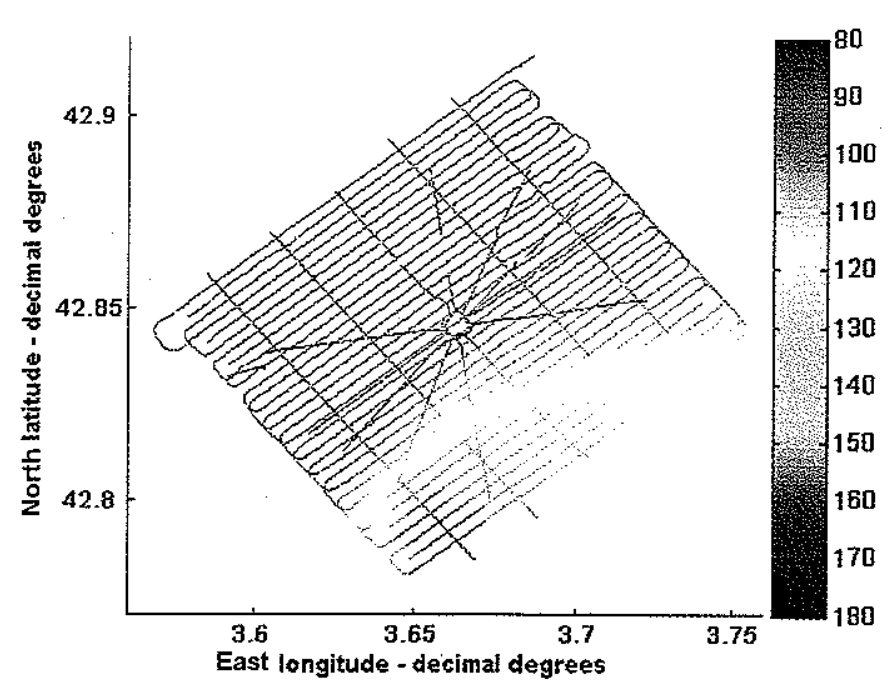

(b)

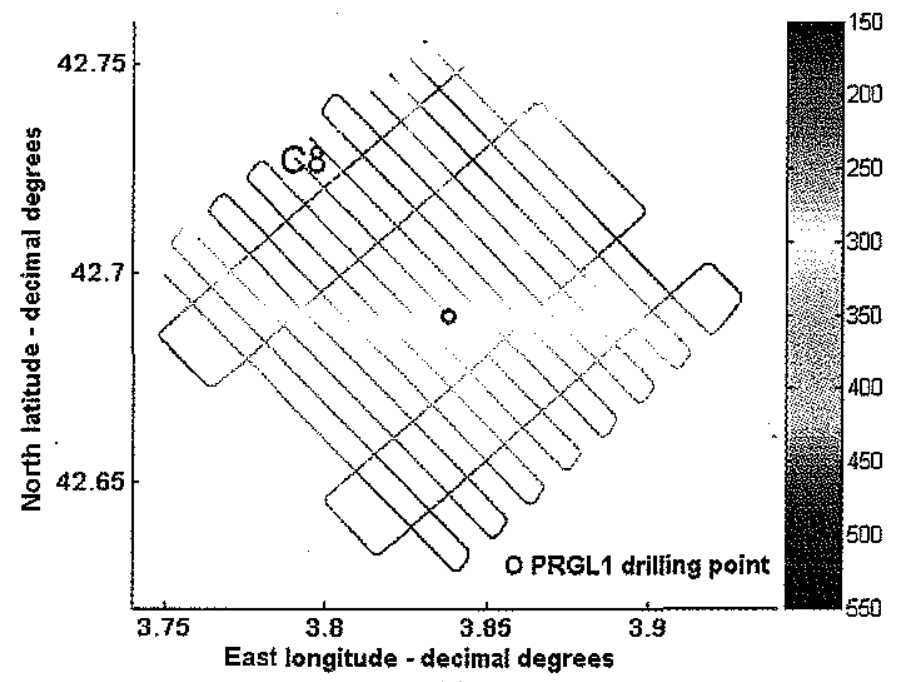

(c)

Fig. 3. Navigation and bathymetry (meters) of the lines recorded over the three areas. (a) CALIMERO area A-tracks and corresponding depth (meters). (b) CALIMERO area B-tracks and corresponding depth (meters). (c) CALIMERO area C-tracks and corresponding depth (meters).

methodology). At the opposite end, a calibration procedure is required to quantify the reflection coefficient from which the impedance contrast can be derived (cf., Section III-B for detailed methodology). To ensure the reliability and the validity of the manufacturer's measurements on the whole spectra, cross correlations have been drawn between the acoustic recordings obtained by the SBP 120 and the in situ measurements by comparing the impedance contrast estimated from the SBP 120 data and those measured in the sampled sediments. The conclusions were that significant discrepancy could happen at lower frequencies with errors up to $20 \%$ as shown in Fig. 5 at abscissa $2600 \mathrm{~Hz}$.

For postprocessing, it was then decided to filter out the lowest band of the SBP 120 . The best frequency band is chosen as the one that minimizes the error between the impedance contrasts estimated from the SBP 120 data and those derived from the in situ measurements (density and speed are measured in the sampled sediments). By filtering the lowest frequencies, the mean error drops to the minimum at $4 \%$ as shown in Fig. 5.

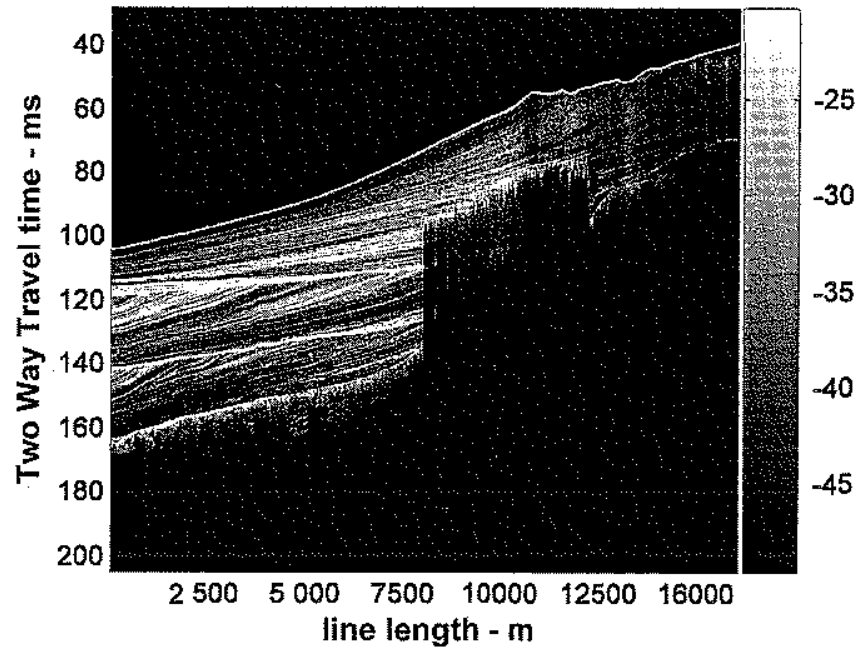

Fig. 4. Example of the SBP 120 seismogram over area A: track AP1 [see location on Fig. 3(a)]. Levels are given in decibels after the preprocessing described in Section $\Pi-\mathrm{C} 4$ and the envelope detection. 


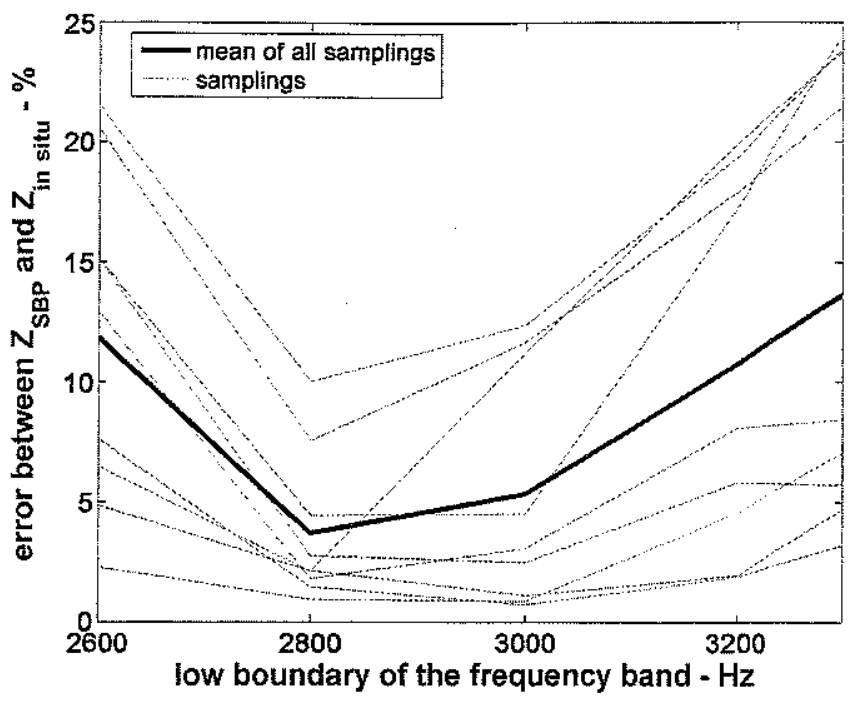

Fig. 5. Determination of the best frequency band by minimizing the error between the impedance contrast estimated from the SBP 120 data $\left(Z_{S B P}\right)$ and those derived from the in situ measurements $\left(Z_{\mathrm{in}}\right.$ situ $)$. The low boundary for the frequency band is taken at $2.8 \mathrm{kHz}$.

As the mean error increases when the frequency bandwidth gets narrower (right-hand side of Fig. 5), all methods are run in the optimal band $(2.8-7 \mathrm{kHz})$ in which the impedance contrast estimates are fully coherent with the in situ measurements.

\section{APPROACH}

In this section, we present the theoretical approach for the quantitative characterization of the geoacoustic parameters from the SBP 120 data.

\section{A. Reflectors Tracking}

The first step of the geoacoustic characterization is the detection and tracking of the reflectors, which indicate the geological structure of the seabed. An automated processing has been defined for this purpose.

1) Detection of the Impedance Contrasts: After preprocessing and envelope detection, the signal exhibits spikes (local maxima), which correspond to the impedance discontinuities, and consequently, to the reflector positions. A conjugate gradient method is used to calculate the local maxima within each track. Only local maxima greater than a given threshold (manually tuned) are detected. An example of the spike detection results is given in Fig. 6.

2) Tracking of the Acoustic Reflectors: The issue of tracking is to associate along a given track spikes detected separately from ping to ping. This problem is tackled using Markov random fields (MRFs) [11], which are commonly used in image processing to represent and segment the spatial information. The use of MRF is relevant because the reflectors in sediments have a spatial correlation much higher than the horizontal resolution of the SBP 120 .

The spatial distribution of the reflectors can be modeled by a lattice of data values $q$, where $q$ is distributed as an MRF taking

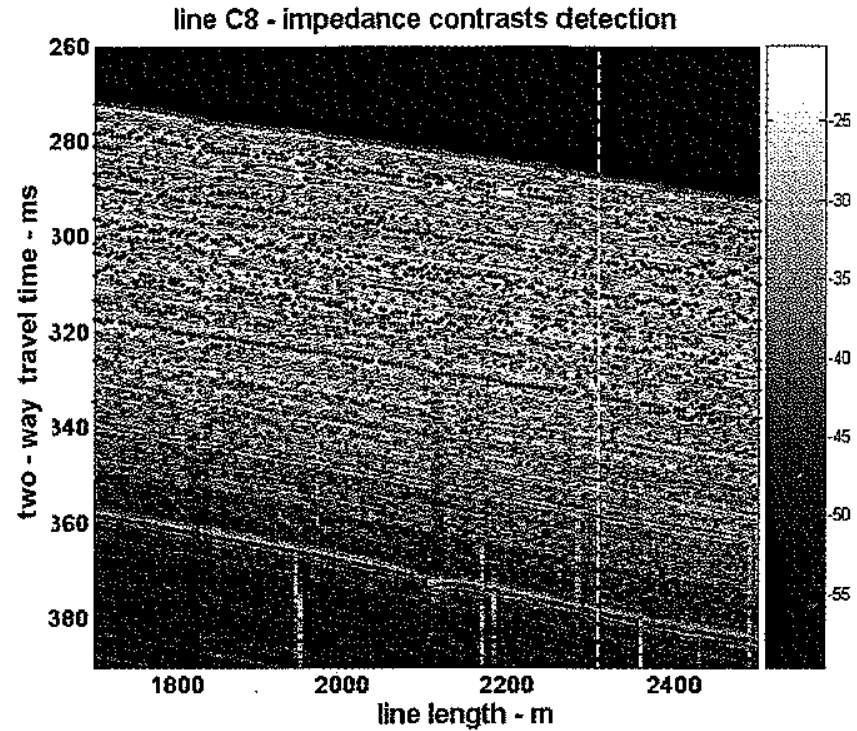

(a)

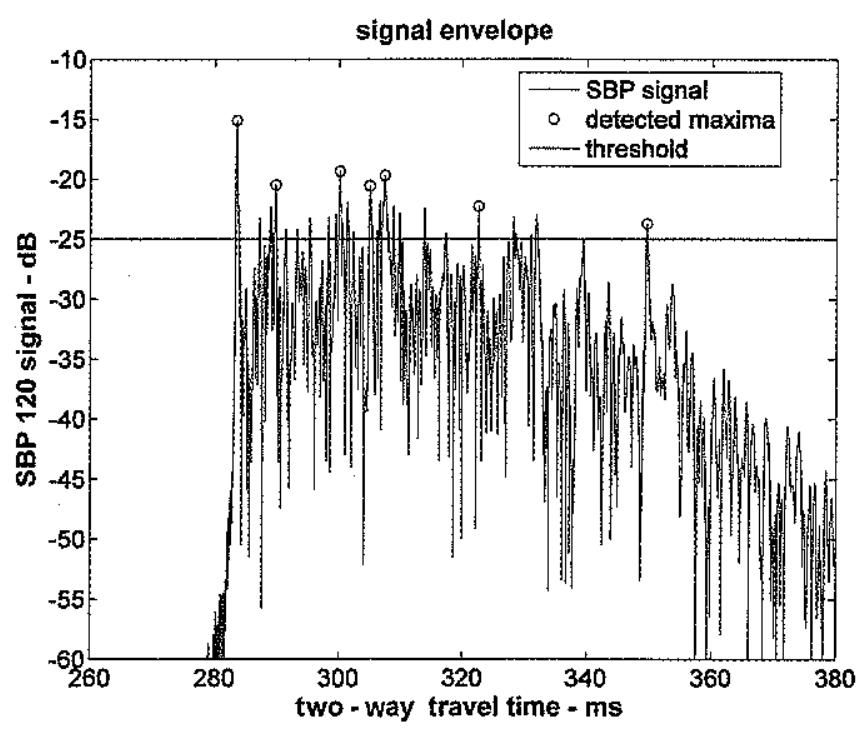

(b)

Fig. 6. Detection of the impedance contrasts. (a) Detected local maxima (red points) are superimposed on the SBP 120 seismogram [line C8; see location in Fig. 3(c)]. (b) One-ping SBP 120 record and corresponding detected reffectors (red circles) for the trace symbolized by the white dashed line in Fig. 6(a). The detected refiectors are the local maxima above the threshold that are not isolated.

values in $\Omega=\{0,1\}$ ( $q=1$ for the presence of a local maximum, $q=0$ otherwise).

The energy function for an autologistic Markov model is defined as

$$
U(q)=\sum_{s}\left(\alpha_{s} q_{s}-\sum_{\substack{t \in V_{S} \\ t \neq s}} \beta_{s t} q_{s} q_{t}\right)
$$

where $q$ is distributed as an MRF taking values in $\Omega=\{0,1\}$, $V_{S}$ is the neighborhood structure associated to $s$, and $\alpha_{s}$ and $\beta_{s t}$ are the parameters of the model that control the extent to which the neighboring points are correlated. When considering 


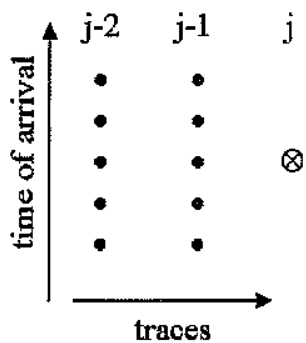

Fig. 7. Chosen neighborhood for the reflector tracking.

$\alpha_{s}=\alpha$ and $\beta_{s t}=\beta, \forall(s, t)$, the conditional distribution of $q$, $\forall q \in \Omega$, can be written as follows:

$$
\begin{aligned}
p(q) & =\frac{1}{Z(\alpha, \beta)} \exp (-U(q)) \\
& =\frac{\exp \left(\sum_{s} q_{s}\left(-\alpha+\sum_{\substack{t \in V_{S} \\
t \neq s}} \beta q_{t}\right)\right)}{Z(\alpha, \beta)}
\end{aligned}
$$

where $Z(\alpha, \beta)=\sum_{q \in \Omega} \exp (-U(q))$ corresponds to a normalization constant.

Finally, the conditional distribution of $q$ is given in

$$
p\left(q_{s} / q_{t}, t \in V_{s}, t \neq s\right)=\frac{\exp \left(q_{s}\left(-\alpha+\sum_{\substack{t \in V_{S} \\ t \neq s}} \beta q_{t}\right)\right)}{1+\exp \left(-\alpha+\sum_{\substack{t \in V_{S} \\ t \neq s}} \beta q_{t}\right)}
$$

The neighborhood structure $V_{S}$ represented in Fig. 7 is relevant to the reflector tracking problem because reflectors of the previous traces are taken into account (even if the times of arrival are slightly different) instead of the neighbors of the same trace (a reflector cannot be vertical). Such a structure takes into consideration the reflector slope to optimize the chance of finding a local maximum in a given trace $j$.

When choosing $\alpha=-\ln (\mu /(1-\mu))(\mu>0, \mu \rightarrow 0)$, the probability of detecting a reflector is very low when no reflector is detected in the neighborhood, which means $q_{t}=0, \forall t \in V_{S}$, $t \neq s$, and it yields

$$
p\left(q_{s}=1 / q_{t}=0, t \in V_{s}, t \neq s\right)=\frac{\exp (-\alpha)}{1+\exp (-\alpha)}=\mu \rightarrow 0 .
$$

In (4), $\mu$ corresponds to the probability that a new reflector begins. If we consider that the probability that a new reflector begins equals the probability that a reflector ends, we can write

$$
\begin{gathered}
p\left(q_{s}=0 / q_{t}=1, t \in V_{s}, t \neq s\right)=\frac{1}{1+\exp (-\alpha+2 \beta)}=\mu \\
\beta=\ln \left(\frac{1-\mu}{\mu}\right)=\alpha \underset{\mu \rightarrow 0}{\mu}+\infty
\end{gathered}
$$

The probability to detect a reflector in trace $j$ tends to 1 if the reflectors are detected in traces $j-1$ and $j-2$

$$
\begin{aligned}
& p\left(q_{s}=1 / q_{t}=1, t \in V_{s}, t \neq s\right)=\frac{\exp (-\alpha+2 \beta)}{1+\exp (-\alpha+2 \beta)} \\
& p\left(q_{s}=1 / q_{t}=1, t \in V_{s}, t \neq s\right) \underset{\alpha=\beta \rightarrow+\infty}{\rightarrow} 1 .
\end{aligned}
$$

The results of the reflector tracking algorithm are presented in Section IV-A.

\section{B. Estimation of the Reflection Coefficient, the Impedance Contrast, and Microroughness}

For normal incidences, if $k \sigma<1$ (small interface roughness), where $k$ is the wave number and $\sigma$ is the seafloor roughness standard deviation, coherent reflection is prevalent compared to the backscattered energy [12]. As our system operates at low frequencies (say below $10 \mathrm{kHz}$ ), it is expected to be able to estimate the magnitude of the surface reflection coefficient accurately $[10]$.

In these conditions, Eckart's model that links the reflection coefficient to the impedance contrast and microroughness versus frequency is valid and can be written as [13]

$$
R_{\text {eckart }}(Z, \sigma, f)=\frac{\frac{Z_{\text {sed }}}{Z_{w}}-1}{\frac{Z_{\text {sed }}}{Z_{w}}+1} \exp \left(-2\left(\frac{2 \pi f}{c}\right)^{2} \sigma^{2}\right)
$$

where $R$ is the reflection coefficient, $Z_{\text {sed }} / Z_{w}$ is the impedance contrast at the sea-bottom interface, $\sigma$ is microroughness, and $c$ the sediment sound speed.

To estimate the impedance contrast and microroughness, the variation of the reflection coefficient with frequency is calculated by cross correlating the preprocessed signal with a series of $331000-\mathrm{Hz}$ band chirps spanning the range between 2.8 and $7 \mathrm{kHz}$ every $100 \mathrm{~Hz}$. The corresponding result $R_{\mathrm{SBP}}\left(f_{i}\right)$ is compared to Eckart's model over the considered frequency band. The impedance contrast and microroughness are the pair $(\hat{Z}, \hat{\sigma})$ that minimizes (least mean squares) the cost function for each ping as expressed in

$$
\operatorname{sce}(Z, \sigma)=\sum_{i=1}^{33}\left(R_{\text {eckart }}\left(Z, \sigma, f_{i}\right)-R_{\mathrm{SBP}}\left(f_{i}\right)\right)^{2} .
$$

\section{Estimation of the Absorption Coefficient}

The absorption coefficient in sediments has been estimated using the spectral ratio method, which is based on the analysis of the frequency content of propagated acoustic waves. This simple approach has already shown its relevance in many applications [14], [15].

In the frequency range used by the SBP 120 , the attenuation coefficient of compressional waves is expected to vary linearly with frequency [16]. The high-frequency part of the signal is rapidly attenuated with the propagation range whereas low frequencies penetrate deeper. Thus, the analysis of the signal's frequency content with the propagation range inside sediments 
makes it possible to estimate the absorption by comparing spectra at different depths

$$
20 \log \frac{A_{2}(f)}{A_{1}(f)}=-\beta f \frac{\left(d_{2}-d_{1}\right)}{c}
$$

where $A_{1}(f)$ and $A_{2}(f)$ are the spectral amplitudes at different depths, $f$ is the frequency (hertz), $d_{1}$ and $d_{2}$ are the two-way travel distances (meters), $c$ is the sound speed in the sediment layer (meters per second), and $\beta$ is the absorption coefficient $(\mathrm{dB} / \lambda)$.

As it was shown in Section III-B, the reflection coefficient depends on frequency. Nevertheless, for narrowbeam systems (the footprint is about $5 \mathrm{~m}$ in areas $\mathrm{A}$ and $\mathrm{B}$, and $50 \mathrm{~m}$ in area C) operating below $10 \mathrm{kHz}$ over a muddy or a sandy seafloor, the total reflected signal approaches that of the reflection from an unperturbed sediment surface [10], so the variation of the reflection coefficient with frequency is not significant for the microroughness values considered in this study. Therefore, we hypothesize that the estimation of the absorption is not affected while the spectra calculated for two distinct acoustic refiectors are divided.

Owing to the wide frequency bandwidth of the SBP 120 , it is possible to estimate accurately the interpolating line of the spectral ratio, whose slope gives an estimate of the absorption coefficient [8]. An example is given in Fig. 8.

For one particular trace, the spectra are calculated over 100 samples (sampling frequency $=20480 \mathrm{~Hz}$ that is to say a 5-ms time window) and are averaged over the 50 neighboring traces to form $A_{1}$ and $A_{2}$. The first spectrum is calculated at the water-bottom interface. The same calculation is done $N$ samples below the seabed ( $N=500$ in Fig. 8 that is to say $24.4 \mathrm{~ms}$ ). Eleven frequencies regularly spaced between 2500 and $7000 \mathrm{~Hz}$ are used to fit the interpolating line to the spectral ratio. Fig. 8 (b) shows the linear variation of the spectral ratio with frequency confirming the previously formulated hypothesis. In this example, the absorption estimate is $0.26 \mathrm{~dB} / \lambda$.

\section{EXPERIMENTAL RESULTS AND DISCUSSION}

In this section, the methods previously described are applied on the SBP 120 data collected during the CALIMERO experiment. The results are compared to the in situ measurements and others sensors.

\section{A. Reflector Tracking}

Fig. 9 shows the detected acoustic reflectors for line C8 [see position in Fig. 3(c)]. First, the algorithm automatically rejects the local maxima below a threshold [see Fig. 6(b)]. Then, it discards the isolated local maxima and the small reffectors. This is the reason why only seven main reflectors have been considered although additional local maxima can be observed in Fig. 6(a). The signal penetration is quite deep (more than 100-ms TWT) due to the presence of soft and fine sediments. The refector position and slope are in good agreement with the maxima of impedance contrasts observed on the recorded data. The deepest reflectors are not detected because the signal is very attenuated at such penetrations, so that SNR is too low and the impedance

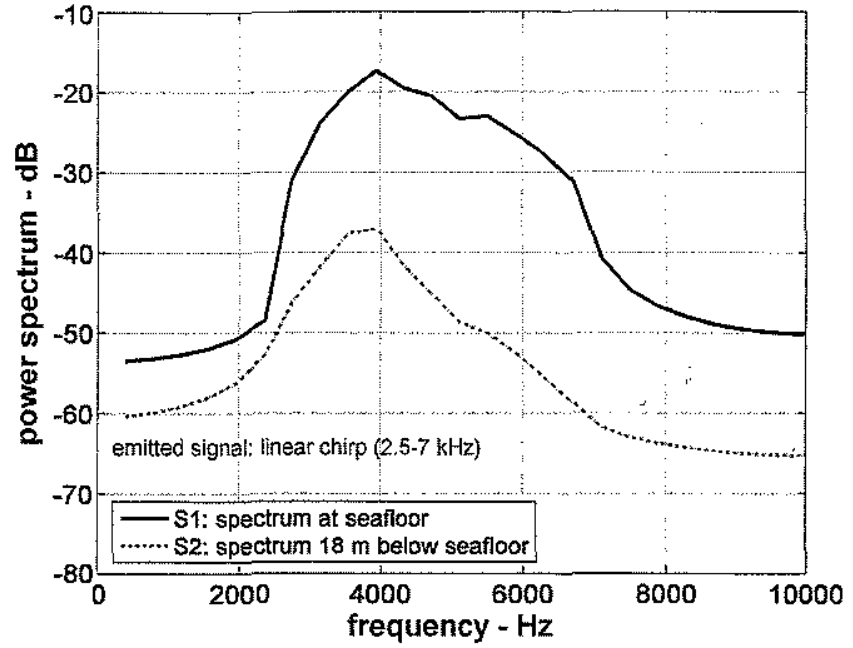

(a)

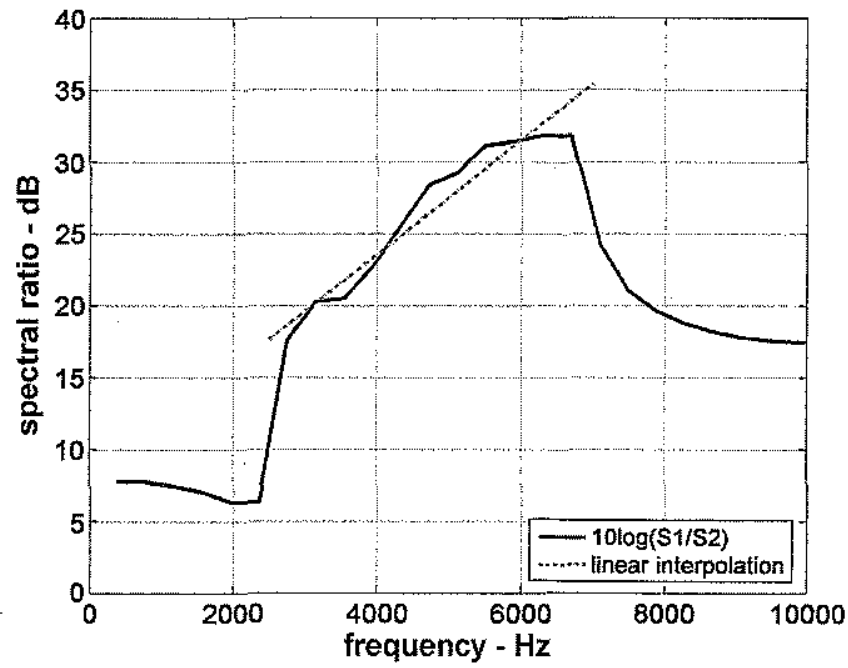

(b)

Fig. 8. Spectral ratio method. (a) Spectra calculated at the bottom and $18 \mathrm{~m}$ below the bottom. (b) Spectral ratio: the stope of the dashed line gives an estimate of the absorption coefficient

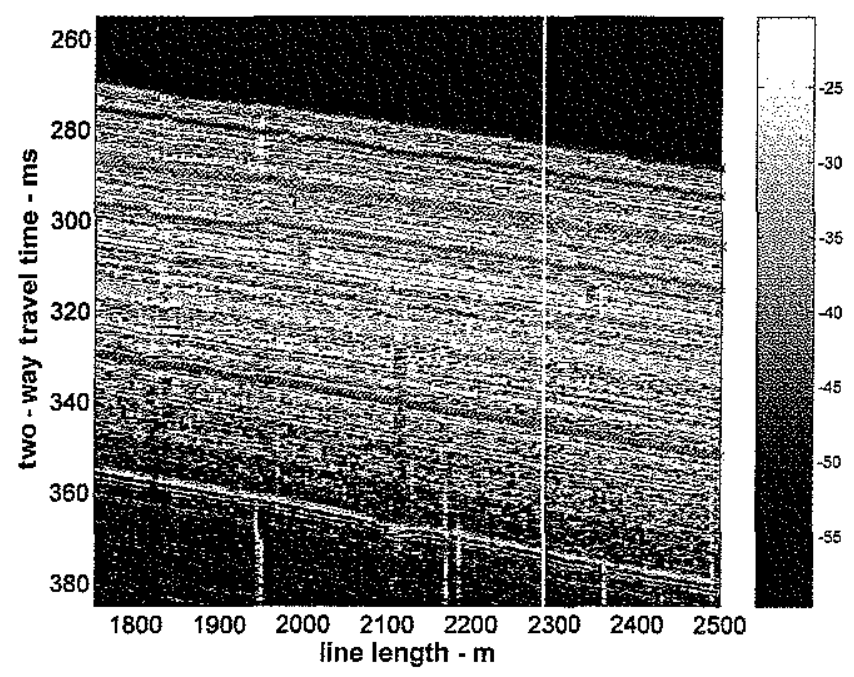

Fig. 9. Reflectors autotracking algorithm for line $\mathrm{C} 8$. The detected reflectors (colored lines) are superimposed on the SBP 120 seismogram (decibels). The white line represents the PRGL1 drill site. 
contrast does not clearly appear on the signal envelope [see Fig. 6(b)].

\section{B. Absorption Coefficient}

1) Preliminary Discussion on the Impact of Intrabed Reflectors on the Absorption Estimates: In Sections IV-B2 and IV-B3, the attenuation estimates are presented for the main reflectors detected with the autotracking algorithm. In Section IV-B4, we calculate the absorption for thick sediment layers to obtain a mean value of the environment attenuation. In both cases, a large number of intrabed reflectors may generate interferences in the signal [17] causing attenuation losses [18] and may degrade the absorption estimates. To address this issue, a preliminary study is presented here to evaluate the effect of intrabed reflectors on the absorption estimates.

At PRGL1 drill site (line C8), the attenuation between the seafloor and the last reflector detected (see Fig. 9) is estimated at $0.10 \mathrm{~dB} / \lambda$. Fig. 10 shows the unsmooth spectra and the spectral ratio at the drill site for 21 neighboring traces (actually, 100 traces have been considered but for readability reasons, the figure shows only every fifth trace). The standard deviation is $3.7410^{-4} \mathrm{~dB} / \lambda$, which tends to point out the significance of the approach and the high confidence bound on the attenuation estimates. This value is then compared to the one calculated for each sediment layer (see Section IV-B2) and averaged by taking into account the layer thickness. The mean value is $0.12 \mathrm{~dB} / \lambda$, which is very close to $0.10 \mathrm{~dB} / \lambda$ obtained above. Thereby, we formulate the hypothesis that, in the SBP 120 frequency band, the attenuation losses due to the intrabed multiples are insignificant. Moreover, in Section IV-B, the spectra are always calculated at the interfaces presenting a step change in impedance (see Fig. 18) and a small transition between the upper and lower sediments. This requirement prevents the intrabed reflector interference from causing peaks and valleys in the spectra.

To conclude, the spectral ratio method proves to be reliable at predicting the absorption estimates provided the requirements formulated by Schock [17] are respected. The inversion method can then be extended to calculate the attenuation of successively deeper or thicker sediment layers.

2) 2-D Estimation Along a Track and Comparison With Drilling: Attenuation has been estimated in 2-D along a surveyed track for each sediment layer delimited by two successive reflectors by combining the reflectors autotracking algorithm and the spectral ratio method. The positions of the time windows in which spectra are calculated are automatically adjusted to the location of the upper and lower boundaries of the sediment layers. In this section, the results are presented and compared to those derived from the in situ measurements.

Fig. 11(a) shows the absorption estimates along line C8 (which passes through the PRGL1 drill site) for the six detected sediment layers (see Section IV-B1). The PRGL1 drilling position is marked by the white vertical line in Fig. 11(a). The corresponding absorption profile calculated from the SBP 120 data is represented by the blue line in Fig. 11(b). The red curves in Fig. 11(b) correspond to the absorption values derived from the parameters measured in sediments. $\Phi$, the mean grain size, in phi units, is known because it is related to the mean grain diameter $d_{\mathrm{mm}}$ (in millimeters), which is measured by

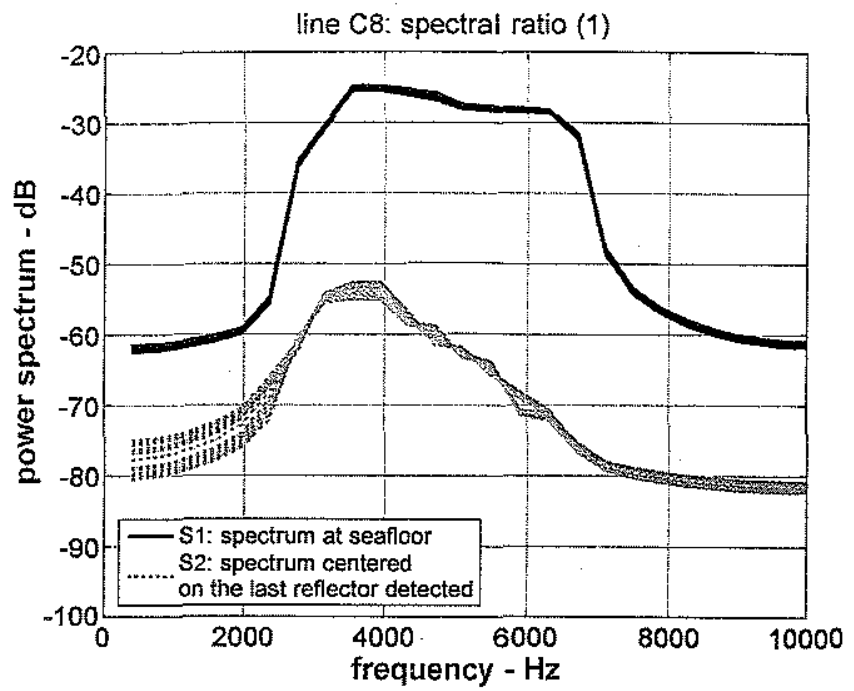

(a)

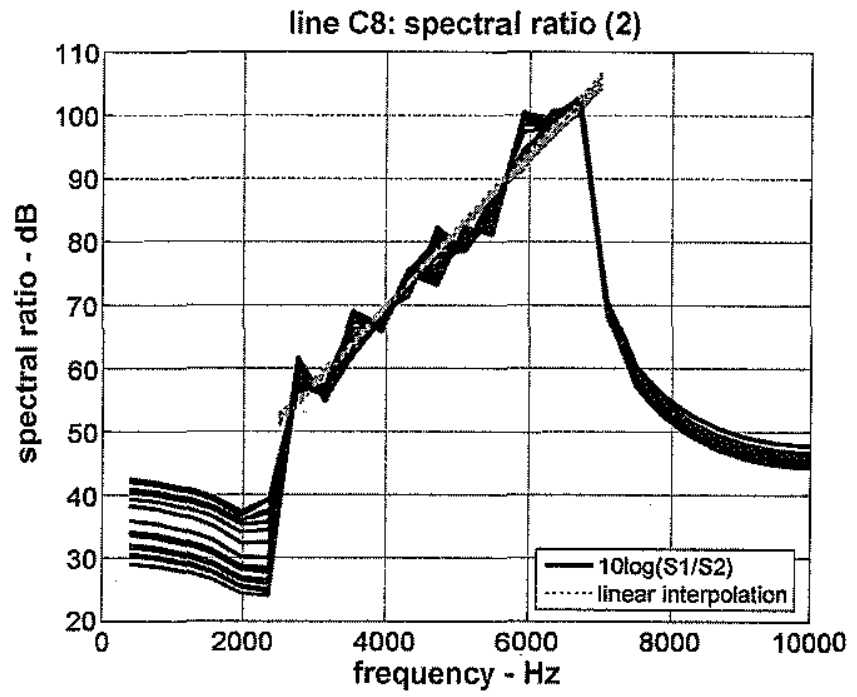

(b)

Fig. 10. Spectral ratio method at PRGL1 drill site. (a) Spectra calculated at the bottom and at the last reflector detected for 21 traces that correspond to the 100 neighboring traces sampled every five traces. (b) Spectral ratio for the 21 traces: the slope of the dashed line gives an estimate of the absorption coefficient.

$\Phi=-\log _{2} d_{\mathrm{mm}}$. The absorption values and the standard deviations are then inferred from Hamilton's empirical model linking the attenuation to the mean grain size [16]. The absorption coefficients are in good agreement with those derived from the drilling, excepted for the layer characterized by a high absorption, whose position is slightly shifted. This difference is probably due to the presence of an interface with a high impedance contrast not detected by the algorithm just below the magenta reflector in Fig. 9. Moreover, Fig. 11(a) displays the horizontal continuity of the absorption estimates along a track. This comparison confirms the validity of the approach.

3) 2-D Estimation Along a Track and Comparison With the VLF Sonar Data: The attenuation estimates have also been tested against the results from very-low-frequency (VLF) sonar transmissions between a towed source $(300-1000 \mathrm{~Hz})$ and a moored vertical array. Data acquired in area $A$ have been processed with a joint time- and frequency-domain technique [4]. 


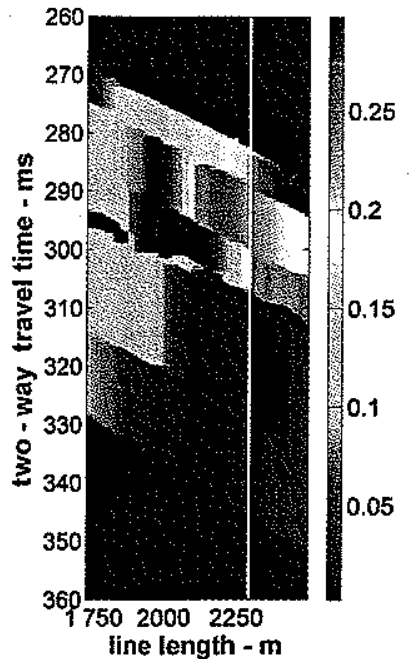

(a)

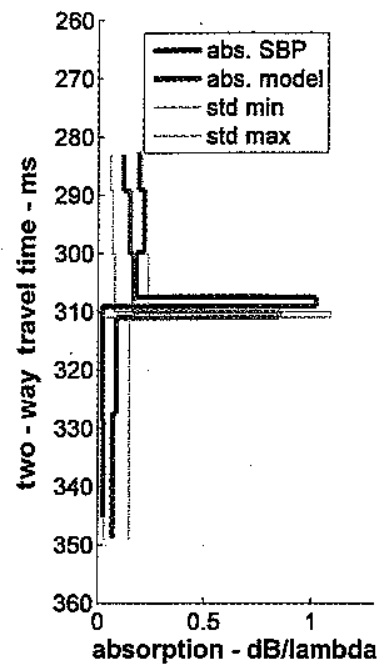

(b)
Fig. 11. Estimation of the absorption for line $\mathrm{C} 8(\mathrm{~dB} / \lambda)$. (a) Absorptions calculated from the SBP 120 data within the sediment layers detected by the refiector autotracking algorithm. (b) Comparison of the absorption profile estimated from the SBP 120 data (blue line) at PRGL1 drill site [symbolized by the white line in Fig. 11(a)] and that calculated from the parameters measured on the drilling (red line). Refer to Fig. 3(c) for the PRGL1 drilling position.

The geoacoustic inversion procedure is divided in two steps. First, the speed and the thickness of each layer are estimated using a seismic reflection approach. Second, the path amplitude variations along a track are used to estimate the density and the absorption [19]. The applicability of this method in the CALIMERO case is valid because area A features shallow waters and a flat bottom so the propagation medium can be reasonably assumed to be range independent. This method gives a model of the stratified bottom with averaged geoacoustic parameters.

The absorption estimates from the SBP 120 have been compared to the results derived from the VLF sonar. The results are shown in Fig. 12: The black dashed curve in Fig. 12(c) represents the absorption estimates for the stratified bottom derived from VLF data using Holland's method [4], [19]. The blue curve corresponds to the average of the absorption profiles between the towed source and the VLF reception buoy (distance $<500 \mathrm{~m}$ ) for the same three layers. The results are here again in good agreement.

The southern part of area $\mathrm{A}$, where the reception array was moored, corresponds to the superficial silty sediments characterized by low absorption coefficients (about $0.1 \mathrm{~dB} / \lambda$ ). The absorption for the deeper layers is higher due to the presence of coarser sediments that appears on the SBP 120 record in Fig. 12(a) with stronger impedance contrasts.

Thus, by combining the spectral ratio method with the results of the refiector autotracking algorithm, it is possible to compute automatically in 2-D the absorption profile along a line recorded by the SBP 120. The two previous examples show that the absorption estimates are in good agreement with the in situ measurements and others sensors deployed during the CALIMERO experiment.

4) Cartography of the Absorption Coefficient: To validate globally the approach, the spectral ratio method has been tested for the three areas surveyed during the CALIMERO cruise. To observe the spatial consistency of the results between the different lines of the survey, the absorption values have been

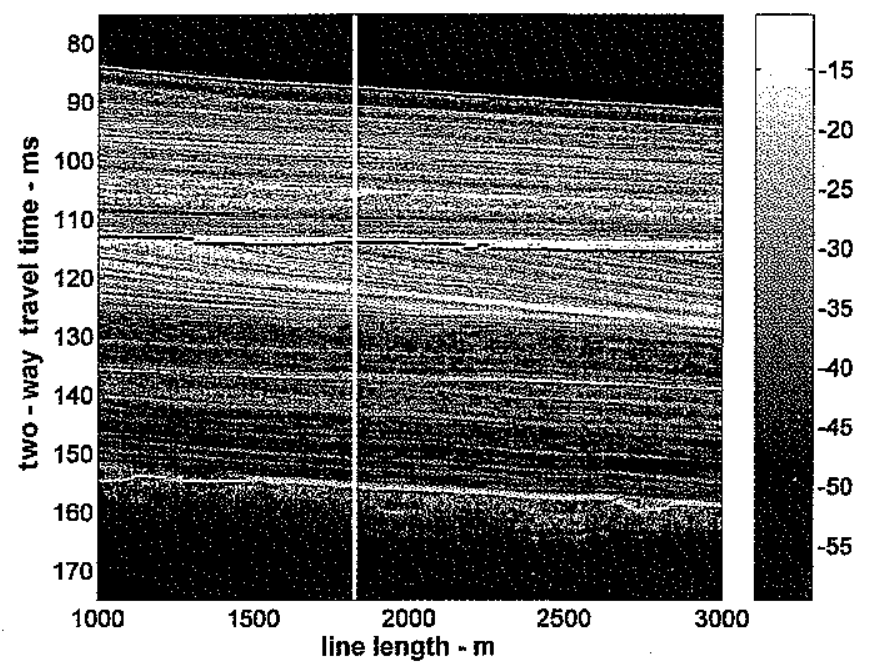

(a)

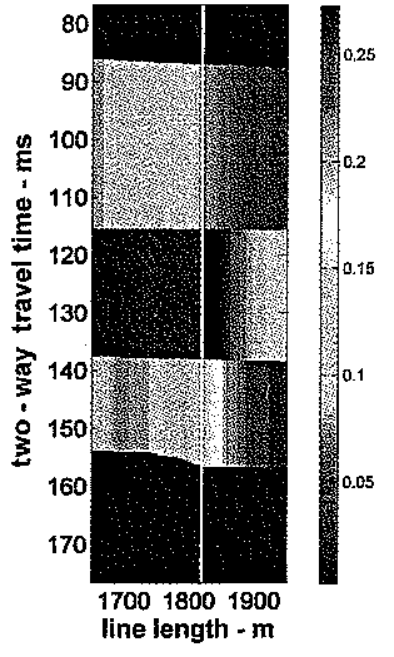

(b)

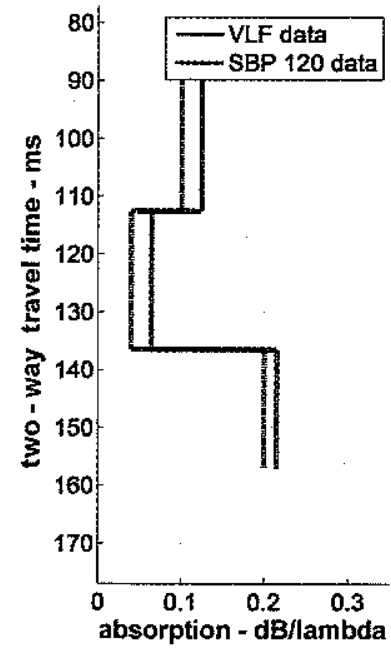

(c)
Fig. 12. Absorption estimates near the VLF sonar reception array [refer to Fig. 3(a) for the array position]. (a) SBP 120 record and main reffectors detected. (b) Absorption profile $(\mathrm{dB} / \lambda)$. (c) Comparison between the SBP 120 and the VLF sonar. The white vertical line indicates the position of the moored reception array.

calculated for a constant thickness of sediments regardless of the reflector position. The sediment layers are arbitrarily chosen thick to obtain a mean value of the environment attenuation. The purpose of such an approach is to simplify the computation of the propagation losses for sonar performance prediction. The results for the three surveyed areas are shown in Fig. 13. The absorption coefficients have been estimated for a 18 -m-thick layer for areas $\mathrm{A}$ and $\mathrm{B}$ (corresponding to 500 samples) and 36 -m-tick layer for area $\mathrm{C}$ (corresponding to 1000 samples) because of the deeper penetration on this site. The maximum values that can be chosen are 500 and 1000 , otherwise signals are contaminated by the first multiple echo.

In area $\mathrm{A}$, the southern part of the area is characterized by low absorption (less than $0.1 \mathrm{~dB} / \lambda$ ) because of the presence of soft sediments, confirmed by the sediment samplings. The northern part shows higher attenuation that indicates the presence of coarser sediments in the first $18 \mathrm{~m}$ below the seafloor. 


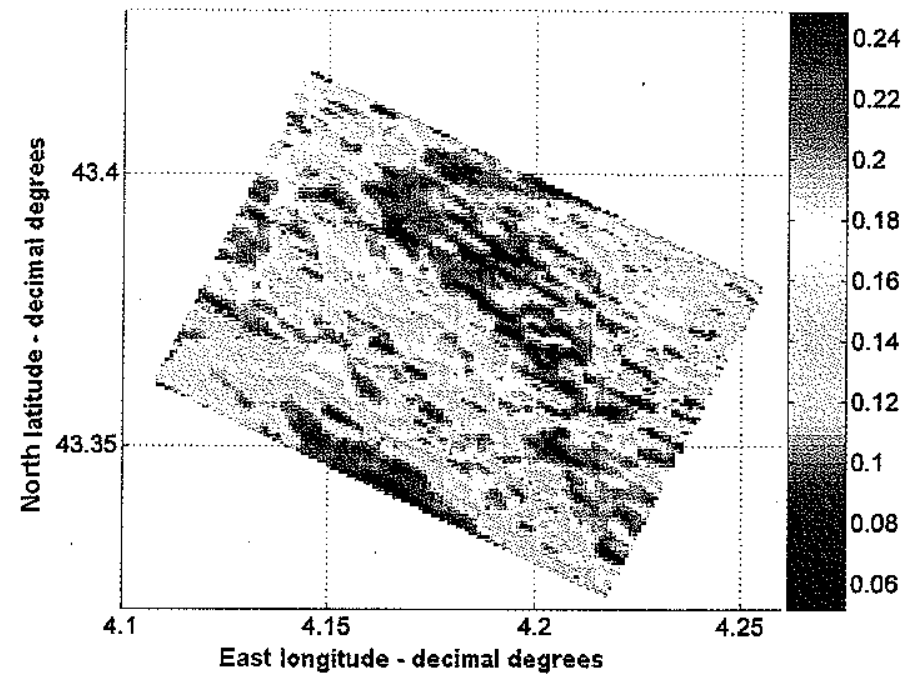

(a)

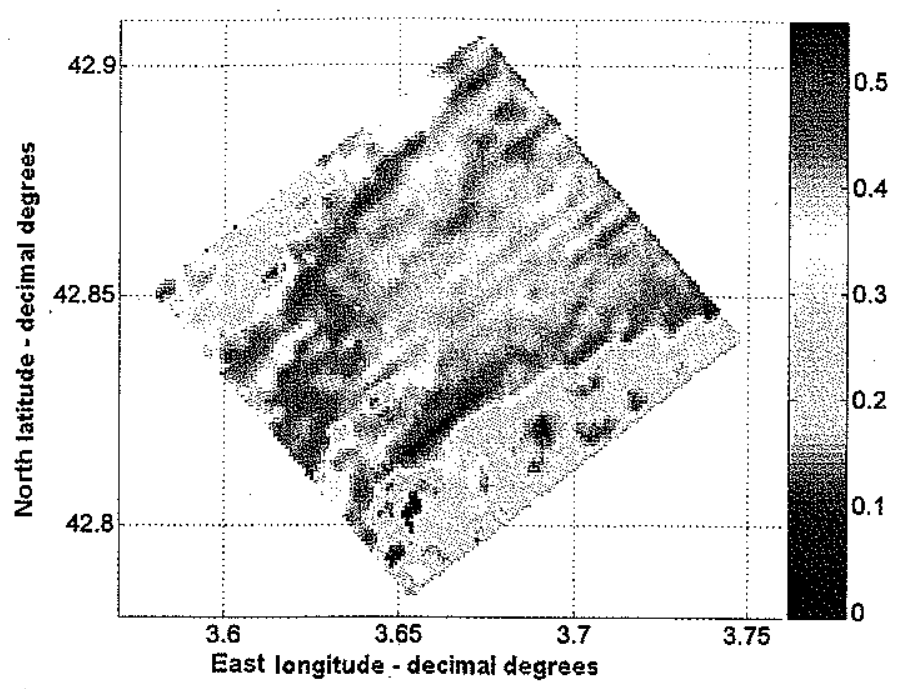

(b)

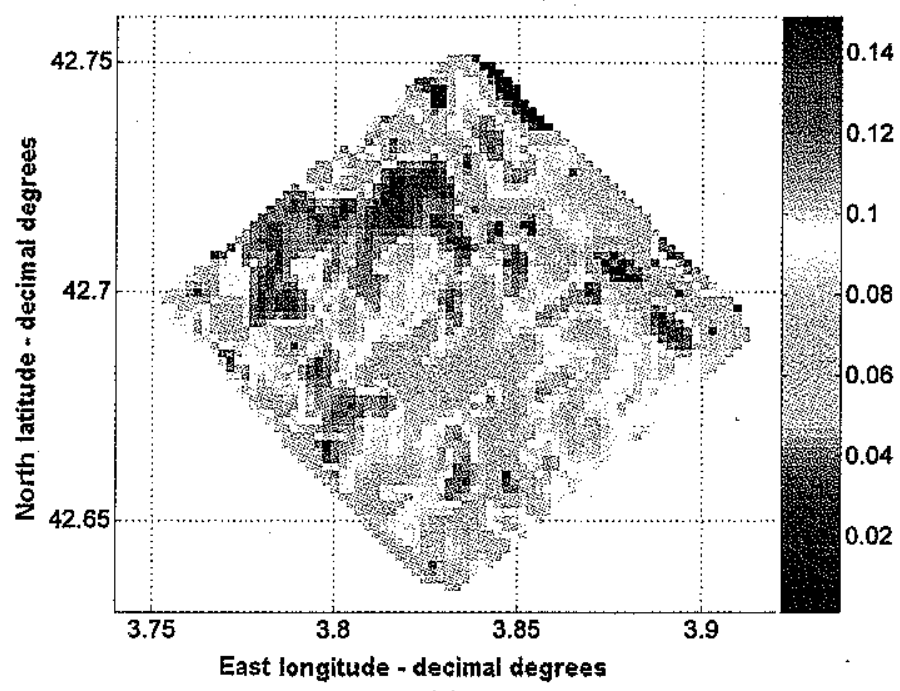

(c)

Fig. 13. Estimation of the absorption coefficients $(\mathrm{dB} / \lambda)$ just below the seafloor. (a) Area $\mathrm{A}$, layer thickness $=18 \mathrm{~m}$. (b) Area $\mathrm{B}$, layer thickness $=18 \mathrm{~m}$. (c) Area C, layer thickness $=36 \mathrm{~m}$.

In area $\mathrm{B}$, the southern part is characterized by low absorption $(0.1 \mathrm{~dB} / \lambda)$, which corresponds to the head of Aude River canyon with the deposits of soft silts. The SBP 120 data recorded on the falling of the canyon have shown a penetration of about $100 \mathrm{~ms}$ two-way travel time, which confirms the presence of soft sediments, as in the northwestern corner of the area. Everywhere else the absorption values are higher (more than $0.3 \mathrm{~dB} / \lambda$ ) because of the presence of sandy sediments. Paradoxically, the so-called Roche de Sète area is characterized by low-absorption values, while being a hard-material area. This is due to a strong scattering of the signal by the rough seafloor interface, canceling the specular reffection. Moreover, we can suspect that the specular direction does not return to the reception array mainlobe due to the sloping seafloor on this rocky site.

In area $C$ [see Fig. 13(c)], the horizontal resolution is lower because of the wider spacing of the lines $(600$ and $200 \mathrm{~m}$ or less for areas $\mathrm{A}$ and $\mathrm{B}$, respectively). The largest penetrations (up to $130 \mathrm{~ms}$ two-way travel time) have been observed in this area, which reveal the presence of soft sediments (i.e., the absorption values under $0.15 \mathrm{~dB} / \lambda$ ). Canyon valleys are characterized by very low absorptions (less than $0.1 \mathrm{~dB} / \lambda$ ) because of the presence of very fine sediment deposits in the basins. Once again, the specular reflection is canceled on the sloping seafloors causing erroneous values in the northeastern part of the area.

These examples show the horizontal consistency of the $a b-$ sorption estimates in sediments. Homogeneous areas appear; moreover, they are in good agreement with the a priori knowledge of the sediment distribution in the surveyed areas (except over significantly sloping seafloors).

\section{Reflection Coefficient}

First, the reflectivity values at the sea-bottom interface have been calculated for the three surveyed areas by estimating the maximum value of the signal envelope. The results are represented in Fig. 14.

Coarse and hard sediments (southern part of area $\mathrm{A}$ and central part of area B) are characterized by high reflectivity values 


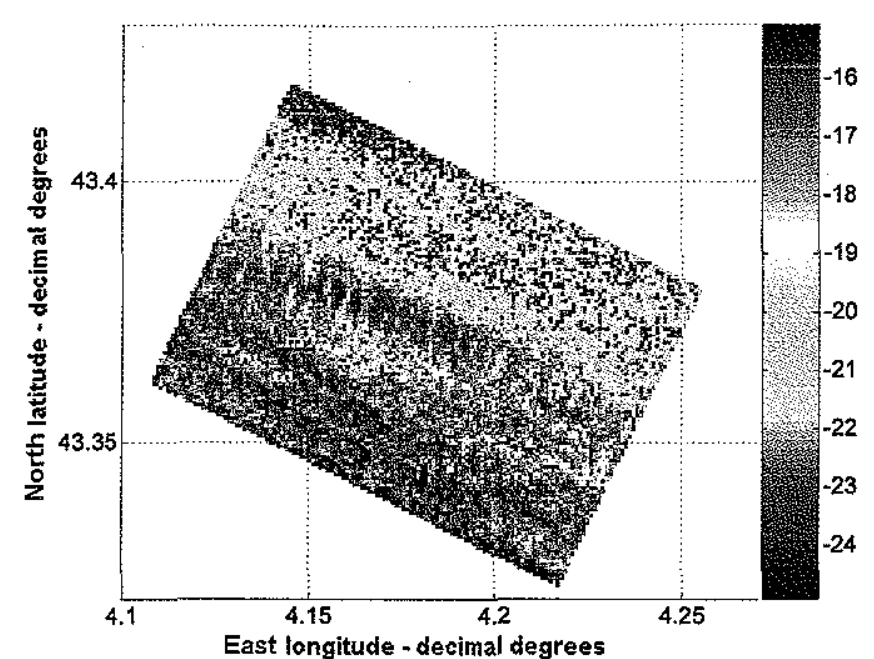

(a)

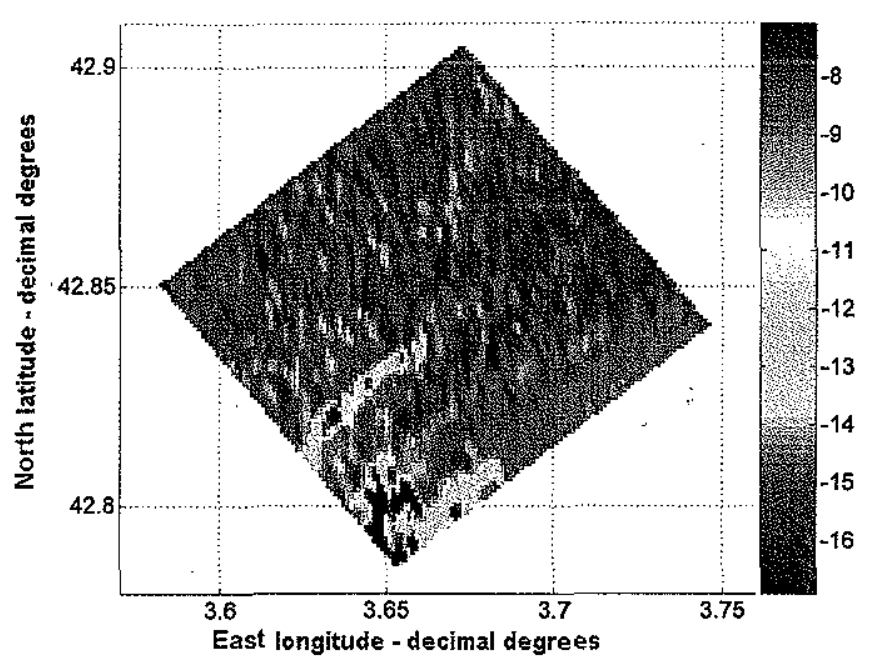

(b)

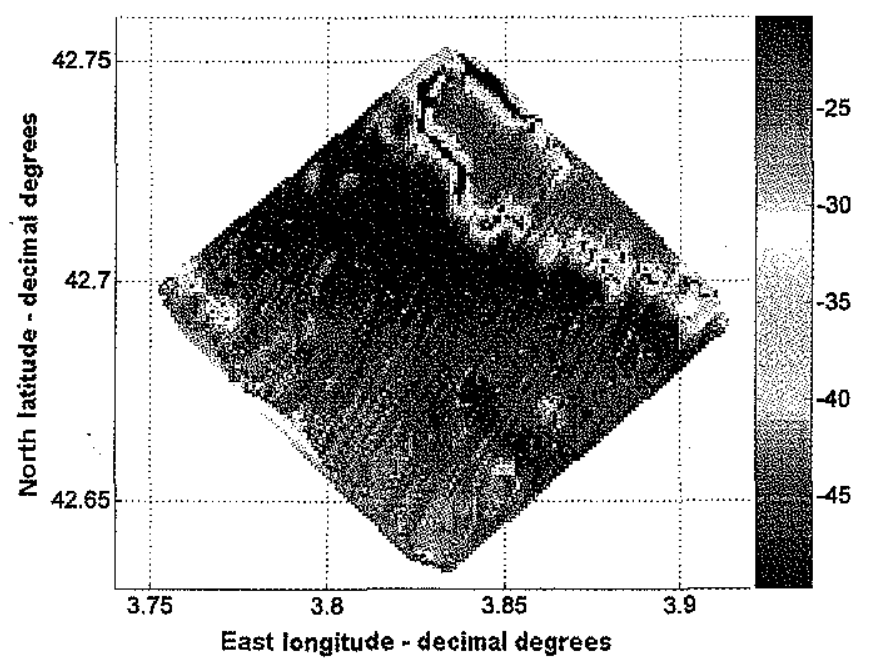

(c)

Fig. 14. Reflectivity (decibels) at the sea-bottom interface. (a) Area A. (b) Area B. (c) Area C.

whereas fine and soft sediments (northern part of area A, southwestern part of area B, and valleys of area C) feature lower values. Sloping seaffoors are characterized by weak reflectivity values because the specular direction does not remain within half the beamwidth and the coherent reflection is not successfully recorded.

The low-attenuation estimates in the southern part of area A [see Fig. 13(a)] interpreted as soft sediments seem to mismatch with the high impedance contrasts [see Fig. 14(a)] corresponding to coarse sediments, and inversely, in the northern part. This is not contradictory because in this section the reflection coefficients are calculated at the sea-bottom interface while the absorption coefficients in the previous section are calculated for an 18- or 36-m-thick layer. Such an approach gives an information of the full sediment column and cannot directly be compared to the surface reflection coefficient.

\section{Acoustic Impedance}

The impedance contrasts have also been calculated with Eckart's model and compared to the in situ measurements.
Inverted microroughness values are not presented because of the insignificant dependency in the environment relevant to the CALIMERO areas.

1) Local Estimation and Comparison With Sampled Sediments: To validate the approach of Eckart, the impedance contrast estimates at the sea-bottom interface have been checked with the various sediment samples collected during the CALIMERO- 1 cruise. Fig. 15 illustrates the inversion principle for one particular grab (BTB120).

Fig. 15(a) represents the reflectivity versus frequency calculated with Eckart's model for several canonical sediment types (sand $Z=2$ or mud $Z=1.2$ ) and microroughness values (rough $\sigma=5 \mathrm{~cm}$ or smooth $\sigma=2 \mathrm{~cm}$ ). Fig. 15(b) shows the variations of the sce function with the impedance contrast and microroughness [see(10)]. On this plot, the sce cost function is displayed by keeping one of the estimated parameters constant and varying the other. The black vertical lines represent the pair $(\hat{Z}=1.93, \hat{\sigma}=3.2 \mathrm{~cm})$ that minimizes the sce function. Fig. 15(c) shows the evolution of reflectivity, derived from the SBP 120 data with frequency at the sampling location (and neighboring traces) and Eckart's model (gray dashed curve) for 


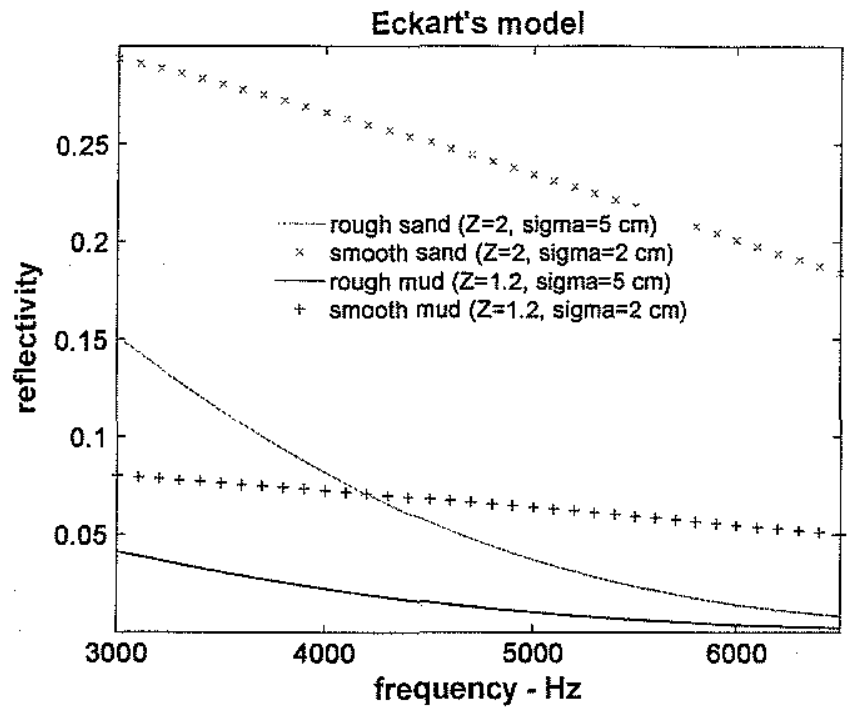

(a)
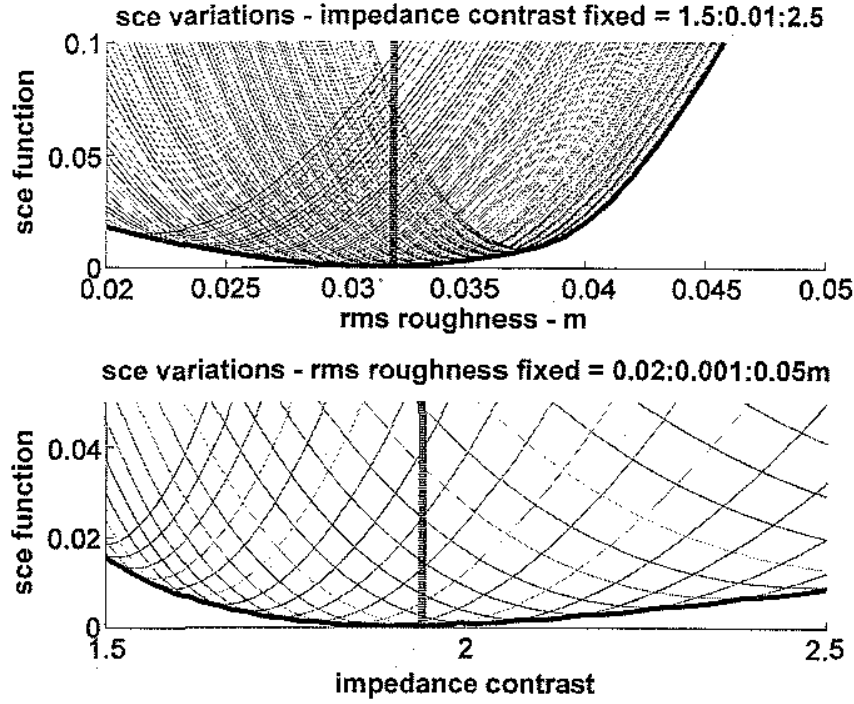

(b)

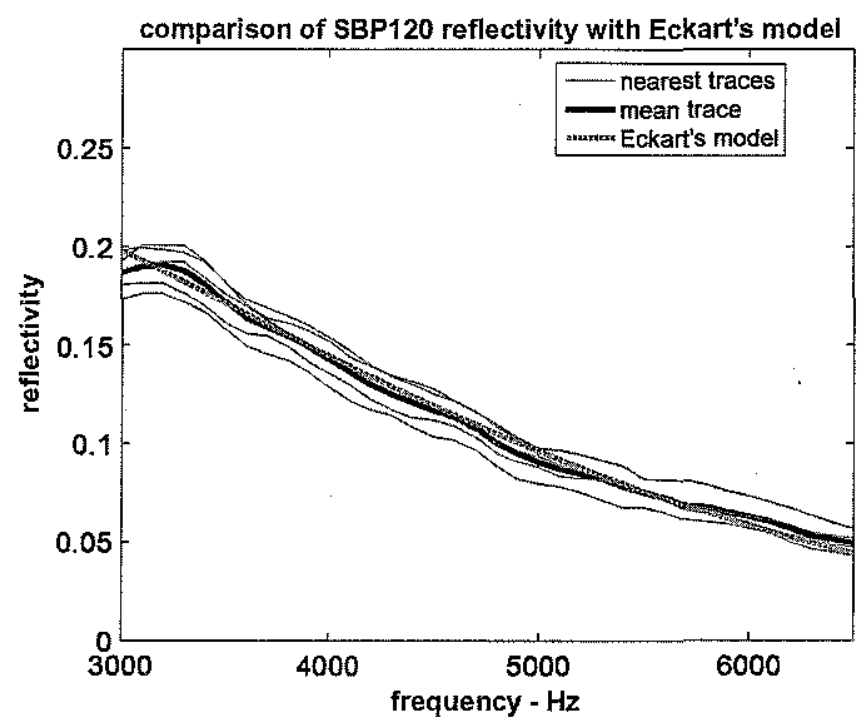

(c)

Fig. 15. Eckart's approach. (a) Eckart's model for several canonical sediments types. (b) Variations of sce cost function with impedance contrast and microroughness. (c) $(\hat{Z}, \hat{\sigma})$ that best fits Eckart's model for grab BTB120 (CALIMERO area A).

$(\hat{Z}, \hat{\sigma})$. An impedance contrast near 1.85 characterizes fine sand, which corresponds to the sampled sediment.

The impedance contrasts calculated from the SBP 120 data have also been compared to the in situ measurements (cores and grabs collected in the areas). The results for sediments sampled in area $A$ are presented in Fig. 16. The positions of the samples are represented in Fig. 17(a).

2) Cartography of Impedance Contrast and Comparison to Sidescan Sonar Data: To observe the spatial consistency of the results between the different lines of the survey, the approach of Eckart has been applied to the data acquired in the three areas. Fig. 17(a) shows the impedance contrast estimates for area $\mathrm{A}$.

The northern part of the area is characterized by low impedance contrasts ( 1.5 or less), because of the presence of soft silty and fine sandy deposits drained by the river Petit Rhône. The southern part of the area is characterized by higher impedance contrasts (about 2.5), which correspond to a sand barrier that crosses the area. Sediments sampled with a grab have shown the presence of gravel and broken shells in this area, confirming the observed high contrasts. Moreover, the impedance contrasts given in Fig. 16 are quite coherent with the geotechnical measurements. This sandy belt was also clearly identified (higher reflectivity) with the sidescan sonar imagery $(455 \mathrm{kHz})$ recorded in parallel with the SBP 120 acquisition [Fig. 17(b)].

3) 2-D Estimation Along a Track and Comparison to Drilling: The calculation of the absorption profile and the impedance contrast at the sea-bottom interface enables the estimation of the impedance in 2-D. First, propagated signals in sediments are corrected from the attenuation estimated with the spectral ratio method. Then, the impedance contrasts are inverted with Eckart's model at each geological interface detected by the reflector autotracking algorithm. Finally, the knowledge of the acoustic impedance in the water column 


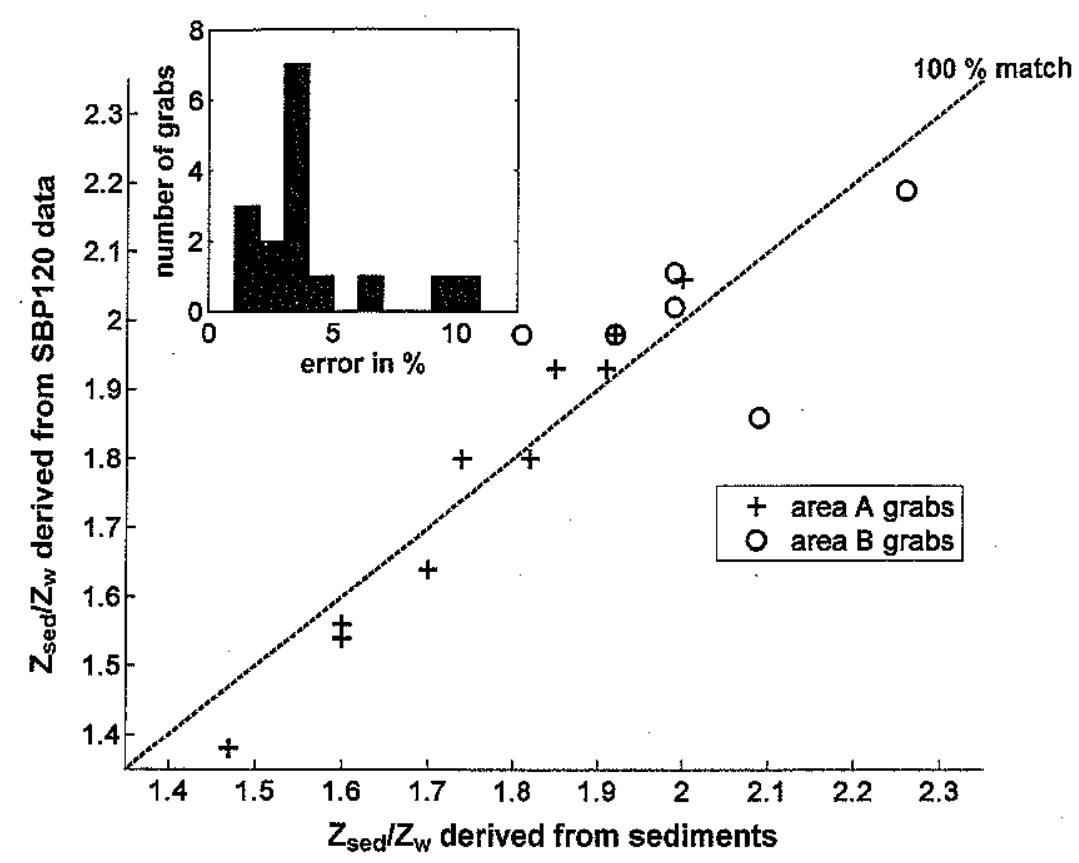

Fig. 16. Comparison of the impedance contrasts $Z_{s e d} / Z_{w}$ at sea-bottom interface derived from the SBP 120 data and the geotechnical measurements from the sediment samples $\left(Z_{\text {sed }}\right.$ and $Z_{\mathrm{w}}$ are, respectively, the impedance in sediment and in water).

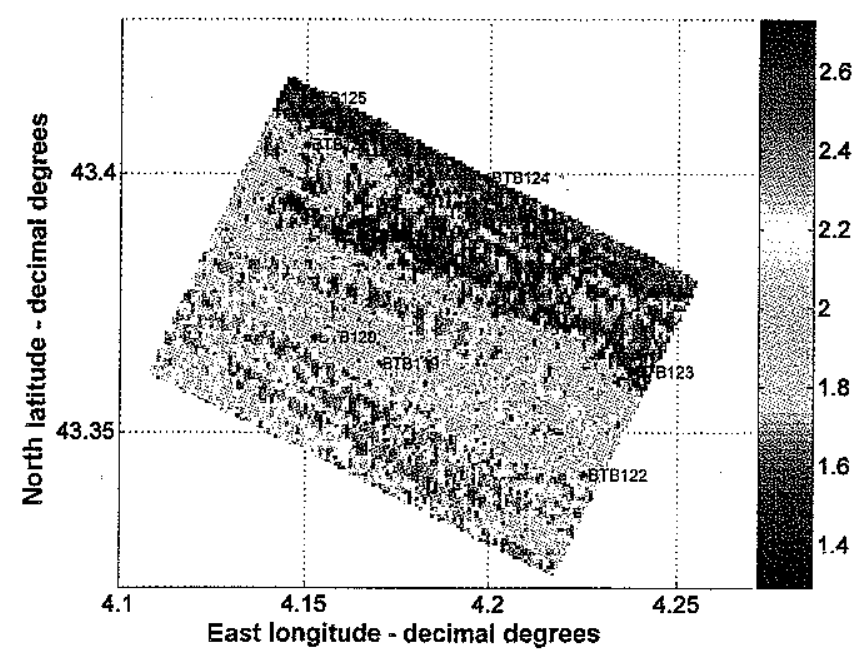

(a)

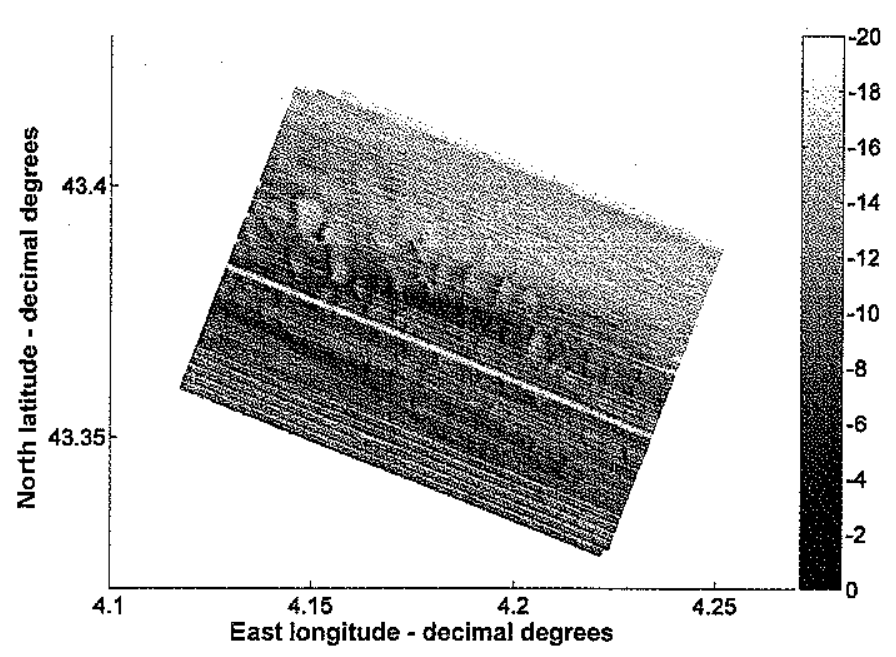

(b)

Fig. 17. CALIMERO area A. (a) Inpedance contrast derived from Eckart's model. (b) High-resolution sidescan sonar mosaic (arbitrary decibel scale because the sidescan sonar is not calibrated).

[measured by the expandable conductivity-temperature-depth (XCTD) probes] enables to infer the impedance profile in sediments.

Fig. 18 shows the estimates of impedance for line C8 and the comparison with PRGL1 drilling. The sound speed and the density in the sampled sediments have been measured. The results are here again in good agreement.

\section{CONCLUSION}

This paper focuses on the estimation of the geoacoustic parameters in sediments from a high-resolution subbottom profiler. First, an algorithm based on MRF was presented for reflector autotracking. Then, the absorption of the compressional waves in sediments was estimated with a spectral ratio method that exploits the spectral content of the propagated acoustic waves in sediments. Finally, the impedance contrast and microroughness were obtained by inversion of Eckart's model. The approach has been applied to the CALIMERO data set. In the three surveyed areas, the geoacoustic estimates were in good agreement with those derived from the in situ measurements. By combining the autotracking algorithm and the geoacoustic parameters inversion methods, it has been possible to infer the sedimentary layers in 2-D (depth and range) along a track. This tends to show that the potential of the SBP 120 , and even more generally subbottom profilers, is high in terms of near real-time modeling of the sedimentary environment.

When operationally implemented, the approach presented here could be of great interest to infer the geoacoustic parameters 


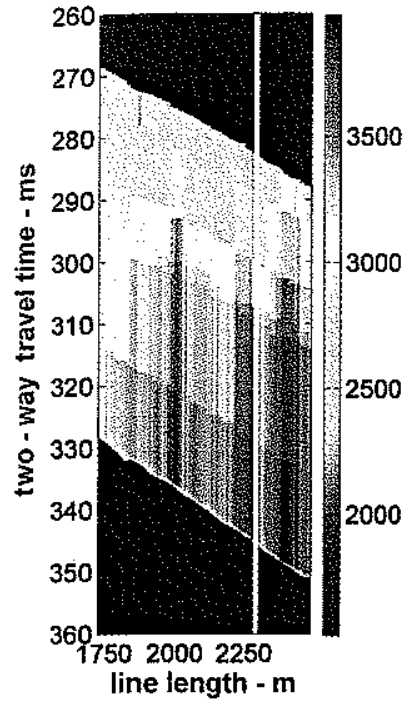

(a)

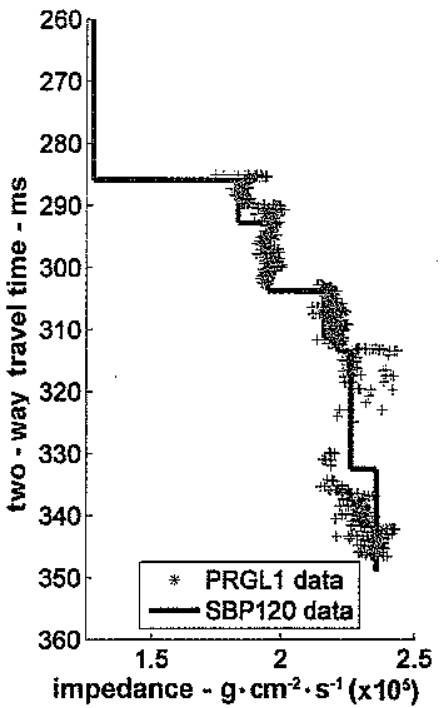

(b)
Fig. 18. Estimation of impedance for line C8. (a) Absorptions calculated from the SBP 120 data within the sediment layers detected by the reflector autotracking algorithm. (b) Comparison of the impedance profile estimated from the SBP 120 data (blue line) at PRGL1 drill site [symbolized by the white line on Fig. 18(a)] and that measured on the drilling (red points). Refer to Fig. 3(c) for the PRGL 1 drilling position.

during precursor antisubmarine warfare (ASW) REA survey without a specific deployment of acoustic equipment (sonobuoy or active source). It can also be a good complement to geoacoustic inversion systems to minimize ambiguities and better constrain the inversion process (prior estimation of the number of layers, search interval of the parameters, etc.). Another application that is under consideration is to implement this method on an AUV-mounted subbottom profiler to assess the geoacoustic parameters for conversion of the ASW REA operations.

In the short term, a study is going to begin to jointly exploit the SBP 120 data and seismic surveys in the CALIMERO areas. In a longer term, further work will consist in merging data and develop the ad hoc data fusion methods to take advantage of the complementarity and redundancy of the systems to build a unique 3-D image of the bottom surface and interior layering. The explored frequency band during the CALIMERO experiment extends from $50 \mathrm{~Hz}$ for seismic to $450 \mathrm{kHz}$ for sidescan sonar; grazing spreads from small angles for sidescan sonar to high ones for subbottom profilers. This multisensor merging process could help understand the influence of the parameters such as roughness and frequency on the reflection or backscattering to improve the characterization of the bottom.

\section{ACKNOWLEDGMENT}

The authors would like to thank S. Berné (IFREMER) and all the partners of the PROMESS European project for giving them access to the data derived from the two drillings. The sidescan sonar KLEIN5000 was gratefully lent and operated by Groupe d'Etudes Sous-Marines de l'Atlantique (GESMA, French Procurement Agency). They would also like to thank X. Lurton (IFREMER) and A. Schimel (formerly at Géosciences Rennes) for their valuable contribution to this work.

\section{REFERENCES}

[1] X. Lurton and J.-C. Le Gac, "The CALIMERO project: Scientific objectives and first at-sea results," in Proc. 1st Sea Tech. Week, In Situ Seabed Characterization, Brest, France, 2004 [Online]. Available: http://www.ifremer.fr/dtmsi/colloques/seatech04/xIurton/A6_Scientific_applications_2/Lurton_LeGac.pdf

[2] J.-C. Le Gac, M. Asch, Y. Stéphan, and X. Demoulin, "Geoacoustic inversion of broadband acoustic data in shallow water on a single hydrophone," IEEE J. Ocean. Eng., vol. 28, no. 3, pp. 479-493, Jul. 2003.

[3] J.-P. Hermand, "Broadband geoacoustic inversion in shallow water from waveguide impulse response measurements on a single hydrophone: Theory and experimental results," IEEE J. Ocean. Eng., vol. 24, no. 1, pp. 41-66, Jan. 1999.

[4] C. Holland and J. Osler, "High-resolution geoacoustic inversion in shallow water: A joint time- and frequency-domain technique," $J$. Acoust. Soc. Amer., vol. 107, no. 3, pp. 1263-1278, 2000.

[5] M. Siderius, P. Nielsen, and P. Gerstoft, "Range-dependent seabed characterization by inversion of acoustic data from a towed receiver array," J. Acoust. Soc. Amer., vol. 112, no. 4, pp. 1523-1535, 2002.

[6] M. Fallat, P. Nieisen, S. Dosso, and M. Siderius, "Geoacoustic characterization of a range dependent ocean environment using towed array data," IEEE J. Ocean. Eng., vol. 30, no. 1, pp. 198-206, Jan. 2005.

[7] S. Berné, G. Jouet, A. S. Alix, M. A. Bassetti, M. Canals, A. Cattaneo, H. Colmenero, B. Dennielou, G. Floch, J. Frigola, N. Frumoltz, J. A. Flores, R. Gelfort, J. Gravalosa, M. Rabineau, D. Ridente, R. Schneider, T. Schoolmeester, F. Sierro, N. Sultan, M. Taviani, E. Thereau, G. Tulloch, N. Thouveny, and H. J. Wallrabe-Adams, "Integrating seismic and core data at PRGL1 and PRGL2 PROMESS drill sites: A first attempt," Geophys. Res. Abstracts, vol. 8, 2006, 02282.

[8] B. Langli and J.-C. Le Gac, "The first results with a new multibeam sub-bottom profiler," in Proc. OCEANS, Kobe, Japan, 2004, vol. 2, pp. $1147-1153$

[9] A. Pacault, G. Theuillon, J.-C. Le Gac, X. Lurton, and B. Langli, "Multibeam sub-bottom profiler: Exploitation of experimental data," in Proc. OCEANS, Brest, France, 2005, vol. 1, pp. 702-708.

[10] N. Chotiros, "Reffection and reverberation in normal incidence echosounding," J. Acoust. Soc. Amer., vol. 96, no. 5, pp. 2921-2929, 1994.

[11] J. Besag, "Spatial interaction and the statistical analysis of lattice systems," J. Roy. Statist. Soc. B, vol. 36, pp. 192-236, 1974.

[12] C. Eckart, "The scattering of sound from the sea surface," J. Acoust. Soc. Amer., vol. 25, no. 3, pp. 566-570, 1953.

[13] H. Medwin and C. S. Clay, Fundamentals of Acoustical Oceanography. New York: Academic, 1998, pp. 577-661.

[14] P. Hauge, "Measurements of attenuation from vertical seismic profiles," Geophysics, vol. 46, no. 2, pp. 1548-1558, 1981.

[15] S. Schock, "Remote estimates of physical and acoustic sediment properties in the South China Sea using chirp sonar data and the Biot model," IEEE J. Ocean. Eng., vol. 29, no. 4, pp. 1218-1230, Oct. 2004.

[16] E. Hamilton, "Geoacoustic modeling of the seafloor," J. Acoust. Soc. Amer, vol. 68, no. 5, pp. 1313-1340, 1980.

[17] S. Schock, "A method of estimating the physical and acoustic properties of the sea bed using chirp sonar data," IEEE J. Ocean. Eng., vol. 29, no. 4, pp. 1200-1217, Oct. 2004.

[18] M. Schoenberger and K. Levin, "Apparent attenuation due to intrabed multiples II," Geophysics, vol. 43, no. 4, pp. 730-737, 1978.

[19] P. Plantevin, J.-C. Le Gac, E. Auger, G. Theuillon, and Y. Stéphan, “A joint seismo-geoacoustic inversion in shallow water using a subsurface towed sound source," J. Mar. Syst., accepted for publication.

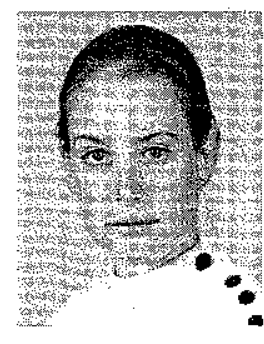

Gwladys Theuillon was born in 1978. She re ceived the engineering degree in hydrogaphy and oceanography from Ecole Nationale Supérieure des Ingénieurs des Etudes et Techniques d'Armement (ENSETA), Brest, France, in 2002.

In 2002, she joined Service Hydrographique et Océanographique de la Marine (SHOM), Brest, France. From 2002 to 2004, she worked as an Hydrographer on the French Navy ship BeautempsBeaupré. Since 2004, she has been a Research Engineer in Underwater Acoustics, involved in rapid environmental assessment studies. 